\title{
A INTRIGANTE BIOQUÍMICA DA NIACINA - UMA REVISÃo CRÍTICA
}

\section{Carlos Alberto Bastos de Maria* e Ricardo Felipe Alves Moreira}

Departamento de Bioquímica, Universidade Federal do Estado do Rio de Janeiro, Rua Frei Caneca, 94, 20211-040 Rio de Janeiro - RJ, Brasil

Recebido em 25/11/10; aceito em 29/3/11; publicado na web em 10/6/11

\begin{abstract}
THE INTRIGUING BIOCHEMISTRY OF THE NIACIN - A CRITICAL REVIEW. Niacin (nicotinamide, nicotinic acid) interferes on homeostasis, DNA regulation, signaling and longevity. Nicotinic acid reduces synthesis of lipoproteins-apo-B and increases HDL. Its antilipemic action in liver produces: 1) inhibition of DGAT2, with decreased triacylglycerol synthesis, 2) downregulation of the $\beta$-chain of adenosine triphosphate synthase, leading to reduced HDL-apo-A-I catabolism. Nicotinic acid could increase redox potential in vascular endothelium. HM74A receptor activation in macrophages would be responsible for the release of prostaglandins, causing flushing in epidermis. HM74A agonists could assist in identifying antilipemic agents. Extended release niacin in combination with statin appears to protect cardiovascular system of patients with low HDL.
\end{abstract}

Keywords: niacin; homeostasis; antilipemic effects.

\section{INTRODUÇÃO}

O termo niacina é um descritor genérico para designar tanto o ácido nicotínico como a nicotinamida. Esses nomes causam grande controvérsia, porque intuitivamente podem ser associados à nicotina do tabaco. De fato, o ácido nicotínico foi identificado pela primeira vez a partir da oxidação da nicotina. ${ }^{1}$ De modo geral, existe uma grande confusão na nomenclatura das vitaminas. O próprio ácido nicotínico já foi designado anteriormente como vitamina PP (fator de prevenção da pelagra). ${ }^{2}$ Neste trabalho de revisão, serão usados os termos: ácido niacínico e niacinamida, em substituição ao ácido nicotínico e à nicotinamida, respectivamente. A niacina, antigamente designada como $\mathrm{B}_{3}$ (terceira vitamina do complexo B a ser identificada), é uma vitamina hidrossolúvel pertencente ao grupo das vitaminas do complexo B. ${ }^{1}$ Sua síntese em humanos é insuficiente para suprir as necessidades metabólicas e, portanto, sua ingestão diária é fundamental. Além disso, a niacina, dependendo da dosagem, apresenta efeito farmacológico. Desta forma, a niacina tem dupla identidade: a primeira como vitamina e a segunda como fármaco.

Esta revisão tem como objetivo abordar aspectos gerais da estrutura química, distribuição, absorção, transporte, excreção, hipo-, hipervitaminose, estado bioquímico e rota metabólica da niacina, bem como suas ações metabólica e farmacológica.

\section{ASPECTOS GERAIS}

\section{Estrutura química e distribuição nos alimentos}

As estruturas químicas do ácido niacínico, da niacinamida e de suas formas coenzímicas, bem como de alguns dos seus precursores e metabólitos são mostradas na Figura 1. A niacinamida é mais solúvel em água, álcool e éter do que o ácido niacínico. Ambos os compostos, quando cristalizados, se apresentam como sólidos brancos e estáveis com absorção máxima a 263 nm. Em solução aquosa, a forma ácida é a mais estável. O ponto de fusão da forma ácida é de $237^{\circ} \mathrm{C}$, enquanto o da forma amida varia de $128-131{ }^{\circ} \mathrm{C}$. O ácido niacínico é anfotérico, formando sais com ácidos e bases. É importante enfatizar que para a atividade vitamínica é imprescindível a presença do anel de piridina com o substituinte ácido $\beta$-carboxílico ou sua amida na posição 3 sem outros substituintes ao longo do núcleo piridínico. Algumas substituições no anel de piridina podem se contrapor à atividade biológica da niacina. Estes compostos incluem: ácido 3-piridino-sulfônico, 3-acetil-piridina, hidrazida do ácido isoniacínico e 6-amino-niacinamida. ${ }^{3,4}$

O triptofano e a trigonelina são precursores do ácido niacínico (Figura 1). O triptofano é um aminoácido aromático, constituinte de diversas proteínas, cuja ingestão diária é obrigatória por ser um aminoácido essencial (não sintetizado no metabolismo humano). Uma parte do triptofano pode ser convertida biologicamente à niacina. ${ }^{5}$ Cabe ressaltar que a niacina é a única vitamina que tem um aminoácido como seu precursor. A trigonelina é um composto nitrogenado presente no café verde. Durante a torra do café, ela sofre pirólise convertendo-se a vários subprodutos, sendo um deles o ácido niacínico. ${ }^{6}$ Neste caso, o grupamento metila da trigonelina é removido, resultando na formação desse ácido. As duas formas coenzímicas da niacina são: a niacinamida adenina dinucleotídio $\left(\mathrm{NAD}^{+}, \mathrm{NADH}+\right.$ $\mathrm{H}^{+}$) e a niacinamida adenina dinucleotídio fosfato $\left(\mathrm{NADP}^{+}, \mathrm{NADPH}\right.$ $+\mathrm{H}^{+}$) (Figura 1). ${ }^{5}$

A niacina é amplamente distribuída nos alimentos de origem animal e vegetal. As principais fontes são carnes, cereais, leguminosas e sementes. Os alimentos ricos em triptofano também são fontes indiretas de niacina. Nas plantas, particularmente em cereais, a niacina está associada por ligação covalente a polissacarídeos e proteínas, sendo chamada niacitina. A niacina conjugada tem biodisponibilidade reduzida, ou seja, baixo valor nutricional. No caso do milho, o pré-tratamento com hidróxido de cálcio, procedimento usado comumente no México e na América Central para preparar a tradicional tortilha, um tipo de pão ázimo (não fermentado), aumenta a biodisponibilidade da niacina. ${ }^{4,5,7-9}$ 
A<smiles>C[n+]1cccc(C(=O)[O-])c1</smiles>

B<smiles></smiles>

D<smiles>NC(=O)c1cccnc1</smiles>

C<smiles>O=C(O)c1cccnc1</smiles>

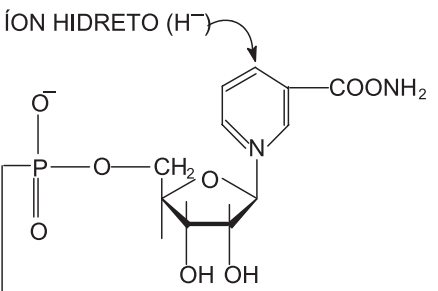

E

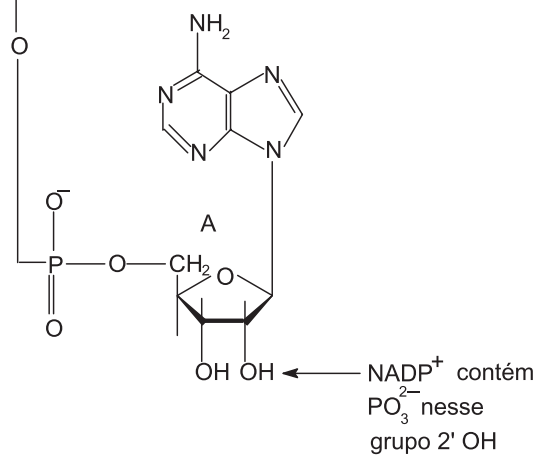

$\mathrm{F}$<smiles>C[n+]1cccc(C(N)=O)c1</smiles><smiles>Cn1cc(C(N)=O)ccc1=O</smiles>

Figura 1. Niacina: precursores, coenzimas e catabólitos. Precursores: A - trigonelina; $B$-Triptofano; Niacina livre: $C$-ácido niacínico; $D$-niacinamida; Coenzimas: $\boldsymbol{E}$ - NAD e NADP; Catabólitos: $F$ - $N^{I}$-metilniacinamida; $G$ - $N^{I}$ metil-2-piridona-5-carboxamida (2-piridona)

\section{Absorção, transporte e excreção}

A niacinamida e o ácido niacínico são rapidamente absorvidos nas mucosas do estômago e do intestino delgado. ${ }^{10}$ Em concentrações fisiológicas, foi caracterizada a existência de um transportador específico, não dependente de sódio, no fígado e em células epiteliais intestinais humanas. No fígado, o transporte de niacina foi dependente de alguns parâmetros: acidez, $\mathrm{pH}$, temperatura e energia. Em altas concentrações, também ocorreria absorção mediada por difusão simples. As coenzimas $\mathrm{NAD}^{+}$e $\mathrm{NADP}^{+}$sofrem hidrólise enzimática por NAD glico-hidrolases intestinais, sendo a niacinamida e o ácido niacínico absorvidos posteriormente., ${ }^{5,10,11}$ Também foi sugerido o envolvimento do sistema $\mathrm{Ca}^{2+} / \mathrm{calmodulina}$ no transporte de niacina em células hepáticas. ${ }^{11} \mathrm{~A}$ niacinamida é a forma predominante no sangue, sendo oriunda da hidrólise das coenzimas no fígado e no intestino delgado. Esses órgãos têm uma grande quantidade de NAD glicohidrolases. Aparentemente, os tecidos captam a niacinamida por difusão simples, porém existem algumas evidências de que o transporte de niacina, particularmente nos eritrócitos, é via difusão facilitada. ${ }^{5}$
Os principais produtos de excreção são: a $\mathrm{N}^{1}$-metilniacinamida e a $\mathrm{N}^{1}$-metil-2-piridona-5-carboxamida (2-piridona) (Figura 1). A S-adenosil-metionina (SAM), o qual é o doador universal de grupamento metila em reações fisiológicas, cede um grupamento metila para conversão da niacinamida à $\mathrm{N}^{1}$-metilniacinamida e derivados pirimidínicos. ${ }^{4}$ Outros catabólitos pirimidínicos minoritários da niacina também são encontrados na urina como, por exemplo, o óxido de $\mathrm{N}^{1}$-metilniacinamida, 4-piridona, $\mathrm{N}^{1}$-metil-4-piridona-3-carboxamida e $\mathrm{N}^{1}$-metil-2-piridona-5-carboxamida. A niacina é metabolizada por outra via metabólica, na qual o ácido niacínico se conjuga com a glicina formando o metabólito chamado ácido niacinúrico, que também é encontrado na urina. A distribuição dos catabólitos na urina é dependente da quantidade e do tipo de niacina que foi absorvida, bem como do estado metabólico de niacina no indivíduo. . $^{512}$

\section{Hipo- e hipervitaminose}

A pelagra é o quadro de deficiência clássica de niacina. É uma doença associada à pobreza e ao alcoolismo e acomete, particularmente, indivíduos sujeitos à monotonia alimentar, tendo como base o uso de um único cereal. A introdução do milho na Europa, a partir do século 18, causou o aparecimento da pelagra em vários países, particularmente na Itália, Espanha e França. Essa doença também provocou inúmeras baixas no sul dos EUA durante os séculos 19 e 20 . Hoje essa doença está restrita a algumas regiões da Ásia e da África, particularmente àquelas na qual a pobreza absoluta é prevalente. ${ }^{8}$

A pelagra caracteriza-se pela doença dos $3 \mathrm{D}$ : dermatite, diarreia e demência. Os sinais mais comuns da deficiência de niacina incluem depressão, apatia, perda de memória e alterações nas mucosas da língua, estômago, trato intestinal e sistema nervoso. As lesões na pele são comumente observadas nos pelagrinos. ${ }^{13}$

Síndromes idênticas à pelagra são observadas por deficiência de outros nutrientes que funcionam como cofatores (por ex., ferro, vitaminas: riboflavina $\left(\mathrm{B}_{2}\right)$ e piridoxina $\left(\mathrm{B}_{6}\right)$ ) de enzimas da via metabólica de conversão do triptofano à niacina. Também na doença de Hartnup, uma desordem genética, ocorre sinais de deficiência da niacina. Nessa doença, a absorção de triptofano dietético é impedida pela ausência de transportador de triptofano na membrana do enterócito. ${ }^{14} \mathrm{O}$ tratamento prolongado com a droga isoniazida poderia provocar deficiência de niacina devido à competição desse fármaco com o piridoxal fosfato, um cofator importante na via metabólica de conversão do triptofano à niacina. ${ }^{15}$

A deficiência de niacina em pacientes com síndrome de imunodeficiência adquirida (SIDA) foi descrita em um estudo científico. Nesse caso, pacientes infectados por HIV apresentaram uma depleção de triptofano no plasma e de $\mathrm{NAD}^{+}$em linfócitos. ${ }^{16}$ Recentemente, foi descrito um caso clínico de pelagra em paciente com câncer esofagiano e alcoolismo. ${ }^{17} \mathrm{~A}$ síndrome carcinoide, uma condição de aumento da secreção de serotonina e catecolaminas por tumores carcinoides, pode também provocar pelagra devido ao desvio de triptofano da dieta para síntese de serotonina, em detrimento da síntese de niacina. ${ }^{5}$

A pelagra deve ser reconhecida em outras condições clínicas, já que é muito fácil de ser tratada, porque caso contrário pode ser fatal. A depleção leve ou moderada de niacina também tem sido alvo de estudos científicos. Uma variedade de proteínas cromossomiais sofre modificações pós-translacionais do tipo difosfato de adenosina (ADP)-ribosilação. Dentre essas proteínas, algumas estão associadas ao reparo do ácido desoxirribonucleico (ADN). Uma das características da deficiência de niacina é o aumento na quebra das fitas de ADN, cujo reparo não ocorre prontamente. Nesse cenário tem sido proposto que a deficiência subclínica de niacina poderia disparar danos celulares, induzindo a neoplasia maligna em células susceptíveis a alterações no mecanismo de reparo do ADN. ${ }^{18} \mathrm{Um}$ estudo mostrou 
que ratos submetidos à deficiência de niacina apresentaram alterações no metabolismo da poli-ADP-ribose, na expressão da proteína p53 e, portanto, tiveram a capacidade da célula reduzida para reparar danos no ADN. ${ }^{19}$ Deficiência de niacina poderia alterar a estabilidade do cromossoma e dificultar o reparo do $\mathrm{ADN}$ in vivo. ${ }^{20}$

Os principais efeitos colaterais (adversos) da niacina ocorrem quando são usadas megadoses dessa vitamina ( $\left.\geq 1 \mathrm{~g} \mathrm{dia}^{-1}\right)$. São observados sintomas como vasodilatação (que causa cefaleia, ardência, comichão e ruborização facial), fadiga, problemas gastrointestinais, hepatopatia e, possivelmente, redução na tolerância à glicose. Também são descritas, em alguns pacientes, alterações degenerativas no músculo quando a niacina é usada em combinação com estatina. O tratamento prolongado com alta dosagem de ácido niacínico poderia agravar o quadro de hiperuricemia (aumento do ácido úrico plasmático). ${ }^{21,22}$ Já a niacinamida causa hepatopatia. ${ }^{23} \mathrm{O}$ uso concomitante da niacina com radioterapia provoca náusea, vômito e disfunção renal e, portanto, é importante monitorar o paciente, sobretudo, aquele com disfunção renal acentuada. ${ }^{21,24}$ De modo geral, os efeitos adversos relacionados à ação vasodilatadora desaparecem com o uso continuado do ácido niacínico e podem ser minimizados com a ingestão de baixas doses de ácido acetilsalicílico ou ibuprofeno. ${ }^{25,26}$ Os mecanismos moleculares envolvidos no surgimento de alguns dos efeitos adversos serão discutidos no tópico ação farmacológica. A ingestão de doses farmacológicas de niacina poderia aumentar dramaticamente as reações de ADP-ribosilação e a expressão de genes envolvidos no metabolismo do $\mathrm{NAD}^{+}$. Alguns resultados, com modelo animal, são sugestivos de que a suplementação com niacina poderia reduzir os efeitos colaterais da quimioterapia, bem como aumentar a morte das células tumorais via ativação do caminho da apoptose dependente de poli-ADP-ribose. ${ }^{27}$ Desta forma, um amplo limite de alterações metabólicas, envolvendo sinalização celular e integridade da cromatina, ocorreriam após a suplementação continuada de ácido niacínico ou niacinamida. A injeção de $1 \mathrm{~g}$ de niacinamida por $\mathrm{kg}$ de peso corporal $\left(1 \mathrm{~g} \mathrm{~kg}^{-1}\right)$ em ratos de laboratório causa fosfatúria, devido ao aumento da concentração de $\mathrm{NAD}^{+}$no córtex renal e à alteração do transporte de fosfato renal. ${ }^{28} \mathrm{~A}$ dose oral letal para o rato é de $3,5 \mathrm{~g} \mathrm{~kg}^{-1}$ para niacinamida e de $4,5 \mathrm{~kg}^{-1}$ para ácido niacínico. Quando niacinamida é adicionada à ração, na concentração de 1-2\%, o crescimento é inibido. ${ }^{29}$

Os requerimentos dietéticos de niacina para a população brasileira, de tal modo que se atinja um estado bioquímico adequado desta vitamina, são baseados nas necessidades dietéticas recomendadas (RDA), as quais foram instituídas por órgãos de saúde dos EUA, após a Segunda Guerra Mundial. Essa RDA varia conforme a idade, sexo e estado fisiológico, dentre outros fatores, e se apresenta no limite de 6-18 equivalentes de niacina (EN) por dia ( $1 \mathrm{EN}=1 \mathrm{mg}$ de niacina ou $60 \mathrm{mg}$ de triptofano). ${ }^{9}$ A dose máxima de niacina recomendada pelo Instituto de Medicina do EUA para população adulta em geral, sem que haja risco de efeitos indesejáveis, é de $35 \mathrm{EN} \mathrm{dia}^{-1}{ }^{25}$

\section{Avaliação do estado bioquímico}

A medição da excreção urinária de nucleotídeos piridínicos majoritários ( $\mathrm{N}^{1}$-metilniacinamida e 2-piridona) é comumente usada para se avaliar o estado bioquímico de niacina no organismo. A $\mathrm{N}^{1}$ metilniacinamida é o metabólito mais usado para monitorar a condição deficiente. Valores menores do que $0,8 \mathrm{mg}_{\text {por }} \mathrm{dia}^{-1}$ indicam estado de hipovitaminose em adultos. ${ }^{30}$ É necessária a coleta de urina durante 24 $h$, já que há uma grande variação diurna na excreção de $\mathrm{N}^{1}$-metilniacinamida. ${ }^{31} \mathrm{~A}$ análise de creatinina é usada para correção desta variação diurna, porém pode ser difícil de se interpretar os resultados, porque a própria excreção de creatinina varia com a idade. ${ }^{5}$ A razão 2-piridona/ $\mathrm{N}^{1}$-metilniacinamida foi sugerida como marcador da deficiência de niacina independente da idade e da excreção de creatinina. ${ }^{30}$ Entretanto, estudos conduzidos com cobaias e humanos indicaram que esta razão é fortemente dependente da ingestão de proteína. ${ }^{32}$ Além do mais, está razão não é adequada para avaliar o estado metabólico de niacina quando a ingestão diária está em torno de 6-10 $\mathrm{EN} \mathrm{dia}^{-1} \cdot{ }^{33}$

A concentração plasmática de niacina e de seus metabólitos é muita baixa e, portanto, não é um marcador útil para monitorar o estado bioquímico desta vitamina. ${ }^{5}$ Entretanto, um estudo experimental indicou que a concentração plasmática de 2-piridona cai abaixo do limite de detecção quando a ingestão de niacina é muita baixa. Quando é dada uma carga oral de niacina (20 mg $70 \mathrm{~kg}^{-1}$ de peso corporal), a concentração de 2-piridona pós-dose é um indicador mais adequado para avaliar o estado de niacina do que a $\mathrm{N}^{1}$-metilniacinamida. ${ }^{33}$ Curiosamente, a concentração de 2-piridona aumenta no plasma e diminui na urina com o decorrer da idade. ${ }^{34}$ Um estudo com indivíduos submetidos a uma dieta experimental deficiente em niacina reduziu em $40 \%$ a concentração plasmática de nucleotídeos piridínicos. ${ }^{35}$ Todavia, estudos subsequentes indicaram resultados conflitantes com relação ao efeito da pelagra ou da dieta experimental sobre a concentração plasmática de nucleotídeos piridínicos. ${ }^{33}$

$\mathrm{O}$ uso da razão $\mathrm{NAD}^{+} / \mathrm{NADP}^{+}$no plasma ou eritrócitos (denominado número de niacina), para avaliar o estado de niacina, tem sido proposto por diferentes autores. ${ }^{36,37}$ Quando sujeitos adultos foram submetidos a uma dieta pobre em niacina a concentração de $\mathrm{NAD}^{+}$no eritrócito caiu apreciavelmente, enquanto a do $\mathrm{NADP}^{+}$não variou. ${ }^{33}$ Isto sugere que a concentração de $\mathrm{NAD}^{+}$no eritrócito seria um indicador sensível para monitorar a depleção de niacina e, quando a razão $\mathrm{NAD}^{+} / \mathrm{NADP}^{+}$fosse menor que 1 , esta poderia identificar indivíduos com risco de desenvolver deficiência de niacina. ${ }^{37} \mathrm{De}$ fato, resultados anteriores obtidos com cultura de fibroblastos, em meio deficiente de niacina, indicaram uma redução na razão $\mathrm{NAD}^{+}$/ $\mathrm{NADP}^{+} .{ }^{38} \mathrm{O}$ número de niacina médio $\left(\left[\mathrm{NAD}^{+} / \mathrm{NADP}^{+}\right]\right.$x 100$)$ para adultos americanos saudáveis é estimado em 175, com um limite de 127-223, para 95\% da população. É bom frisar que o estado bioquímico de niacina varia amplamente entre populações diferentes e é modulado pela suplementação de niacina. ${ }^{5}$

\section{Rota biossintética e sua regulação}

O catabolismo do triptofano pode seguir diferentes rotas metabólicas, incluindo a conversão à niacina e suas coenzimas relacionadas. A conversão do triptofano à niacina segue a via metabólica da quinurenina, na qual o resultado final é a conversão do ácido quinolínico ao ribonucleotídeo do ácido niacínico, sendo esta reação catalisada pela enzima quinolinato fosforribosiltransferase (Figura 2). ${ }^{3}$ Entretanto, a via catabólica predominante é a oxidação do triptofano a glutarato e, eventualmente, a reciclagem não enzimática a ácido picolínico, o qual é excretado na urina (Figura 2). Por outro lado, no fígado, a picolinato carboxilase tem baixa atividade enzimática, proporcionando um acúmulo transitório do semialdeído 2-amino-3-carboximucônico. Este último, que está no ponto de ramificação da via, tende a submeter-se, parcialmente, à ciclização não enzimática formando o ácido quinolínico. Este, por sua vez, é convertido ao ribonucleotídeo do ácido niacínico pela enzima quinolinato fosforribosiltransferase. Note que o fosforribosilpirofosfato fornece um resíduo de ribonucleotídeo para que a última reação ocorra..$^{3,5,39}$

Na espécie humana, a biossíntese de niacina a partir do aminoácido essencial triptofano é uma rota fundamental para se atingir a necessidade bioquímica desta vitamina. Grandes variações na eficiência de conversão de triptofano a niacina têm sido descritas em indivíduos saudáveis. ${ }^{40} \mathrm{~A}$ eficiência de conversão do triptofano dietético à niacina é afetada por uma variedade de fatores hormonais e nutricionais. As vitaminas $\mathrm{B}_{6}$, $\mathrm{B}_{2}$ e o ferro são fatores essenciais para enzimas envolvidas nessa via 

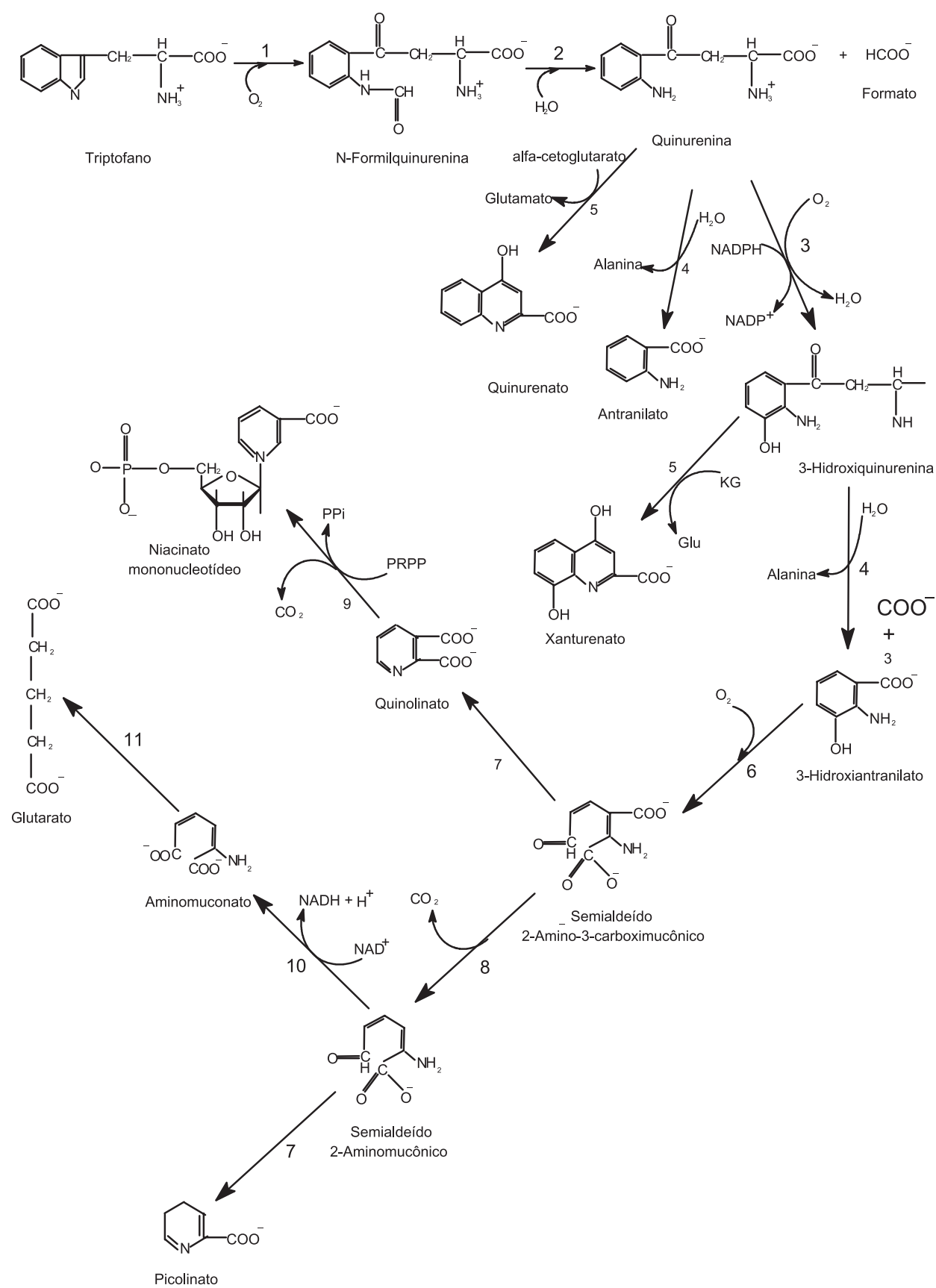

Figura 2. Catabolismo do triptofano. Identificação das enzimas: 1 - triptofano oxigenase; 2 - quinurenina formamidase; 3 - quinurenina hidroxilase; 4 - quinureninase; 5 - aminotransferase; 6 - 3-hidroxiantranilato oxidase; 7 - reação espontânea; 8 - picolinato carboxilase; 9 - quinolinato fosforribosiltransferase; 10 - aldeído desidrogenase; 11 - via metabólica cujo produto final é o glutarato

metabólica. A eficiência de conversão aumenta com a restrição calórica, de proteína, de triptofano e de niacina por causa de alterações na atividade de enzimas da via metabólica, particularmente, a triptofano oxigenase (converte triptofano a $\mathrm{N}$-formil-quinurenina) e a quinolato fosforribosiltransferase (Figura 2). ${ }^{3,41}$ As mulheres gestantes ou as que usam estrogênios sintéticos, como contraceptivos orais, apresentam uma eficiência três vezes maior na conversão do triptofano à niacina. Presumivelmente, um aumento na concentração plasmática do hormônio estrogênio ou de derivados sintéticos estimularia a atividade da triptofano oxigenase que é a enzima, provavelmente, responsável pela regulação da velocidade dessa via metabólica. ${ }^{42}$ Em contrapartida, o estrogênio poderia inibir a enzima quinurenina hidroxilase (converte quinurenina a 3-hidroxiquinurenina), uma outra enzima da via, tornando as mulheres, com concentrações fisiológicas de estrogênio, mais suscetíveis à deficiência de niacina. ${ }^{39}$ Provavelmente, concentrações fisiológicas de estrogênio, embora resultassem na inibição da quinurenina hidroxilase, não teriam um efeito estimulatório relevante sobre a triptofano oxigenase, tornando a mulher mais suscetível à deficiência de niacina.

Um desequilíbrio no balanço de aminoácidos, particularmente um excesso de leucina na dieta, parece antagonizar a conversão de triptofano a niacina através da redução da atividade da quinureninase (Figura 2). ${ }^{43}$ Também há evidências de que a adição de $5 \%$ de leucina à dieta aumentou a atividade do $\mathrm{NADP}^{+}$glico-hidrolase e, portanto, diminuiu a concentração de $\mathrm{NAD}^{+} .{ }^{44}$ Em contrapartida, alguns estudos em ratos e humanos submetidos a dietas acrescidas de leucina indicaram que não houve qualquer efeito adverso sobre 
o metabolismo da niacina. Portanto, se a suplementação de leucina compromete ou não o estado bioquímico de niacina, isto ainda permanece não esclarecido.

As coenzimas $\mathrm{NAD}^{+}$e NADP ${ }^{+}$são sintetizadas em todos os tecidos a partir do ácido niacínico, da niacinamida, ou de ambos. ${ }^{45} \mathrm{O}$ metabolismo do NAD é mostrado na Figura 3. A concentração tecidual do NAD ${ }^{+}$ parece ser regulada pela concentração de niacinamida extracelular, a qual está sob regulação hepática. No fígado, a niacinamida é convertida a $\mathrm{NAD}^{+}$em sua forma não ligada e a metabólitos da niacina, que são excretados na urina. Trabalho conduzido com ratos mostrou que a síntese hepática de $\mathrm{NADP}^{+}$é feita predominantemente a partir do triptofano e não da niacina pré-formada. ${ }^{46} \mathrm{~A}$ niacinamida formada pela degradação do $\mathrm{NAD}^{+}$pode ser reconvertida a $\mathrm{NAD}^{+}$via ribonucleotídeo da niacinamida. A niacinamida também pode ser convertida a ácido niacínico pela niacinamida desaminase. Os hepatócitos contêm pouca niacinamida desaminase, porém niacinamida pode ser desaminada no trato intestinal pela microbiota. ${ }^{47} \mathrm{~A}$ hidrólise de $\mathrm{NAD}^{+}$hepático permite a liberação de niacinamida, que é transportada para tecidos que não têm a habilidade de sintetizar $\mathrm{NADP}^{+}$a partir do triptofano.

\section{FUNÇÕES METABÓLICAS}

\section{Ação coenzímica}

A niacina é essencial na forma das coenzimas $\mathrm{NAD}^{+} / \mathrm{NADH}$ e $\mathrm{NADP}^{+} / \mathrm{NADPH}$, na qual a parcela representada pela niacinamida funciona como um aceptor de elétrons em reações catabólicas ou, como um doador de elétrons em reações anabólicas. Estas coenzimas participam em muitas reações biológicas de óxido-redução e são importantes para a manutenção do estado redox da célula. Enquanto o $\mathrm{NAD}^{+}$está presente em diferentes compartimentos da célula, o $\mathrm{NADP}^{+}$é encontrado basicamente no ambiente citossólico. Cada coenzima está associada por ligação não covalente à porção apoenzima de desidrogenases (membros da família das oxidorredutases) e, portanto, funciona mais como cossubstrato do que grupo prostético destas enzimas. Quando na forma oxidada $\left(\mathrm{NAD}^{+}\right.$e $\left.\mathrm{NADP}^{+}\right)$, elas possuem uma carga positiva porque o grupo amino no anel aromático é uma amina quartenária. Em reações catabólicas, um átomo de hidrogênio do substrato é transferido como íon hidreto para a porção niacinamida do $\mathrm{NAD}^{+}$ou NADP ${ }^{+}$para render a forma reduzida. Outro hidrogênio permanece em solução na forma de próton. Deste modo, a coenzima reduzida é representada como $\mathrm{NADH}+\mathrm{H}^{+}$ou NADPH $+\mathrm{H}^{+}$(Figura 1). Em reações anabólicas, as coenzimas reduzidas da niacina são usadas por enzimas que catalisam a transferência simultânea de dois elétrons. ${ }^{4,5,8}$

A coenzima $\mathrm{NAD}^{+}$participa como cossubstrato das reações de óxido-redução no metabolismo oxidativo. Como exemplo de enzimas que têm o NAD ${ }^{+}$como cossubstrato tem-se: piruvato desidrogenase, que catalisa a conversão do piruvato a acetil-CoA, a $\alpha$-cetoglutarato desidrogenase, enzima do ciclo de Krebs que catalisa a conversão do $\alpha$-cetoglutarato a succinil-CoA e a acil-CoA desidrogenase, enzima da $\beta$-oxidação de ácidos graxos que catalisa a conversão do

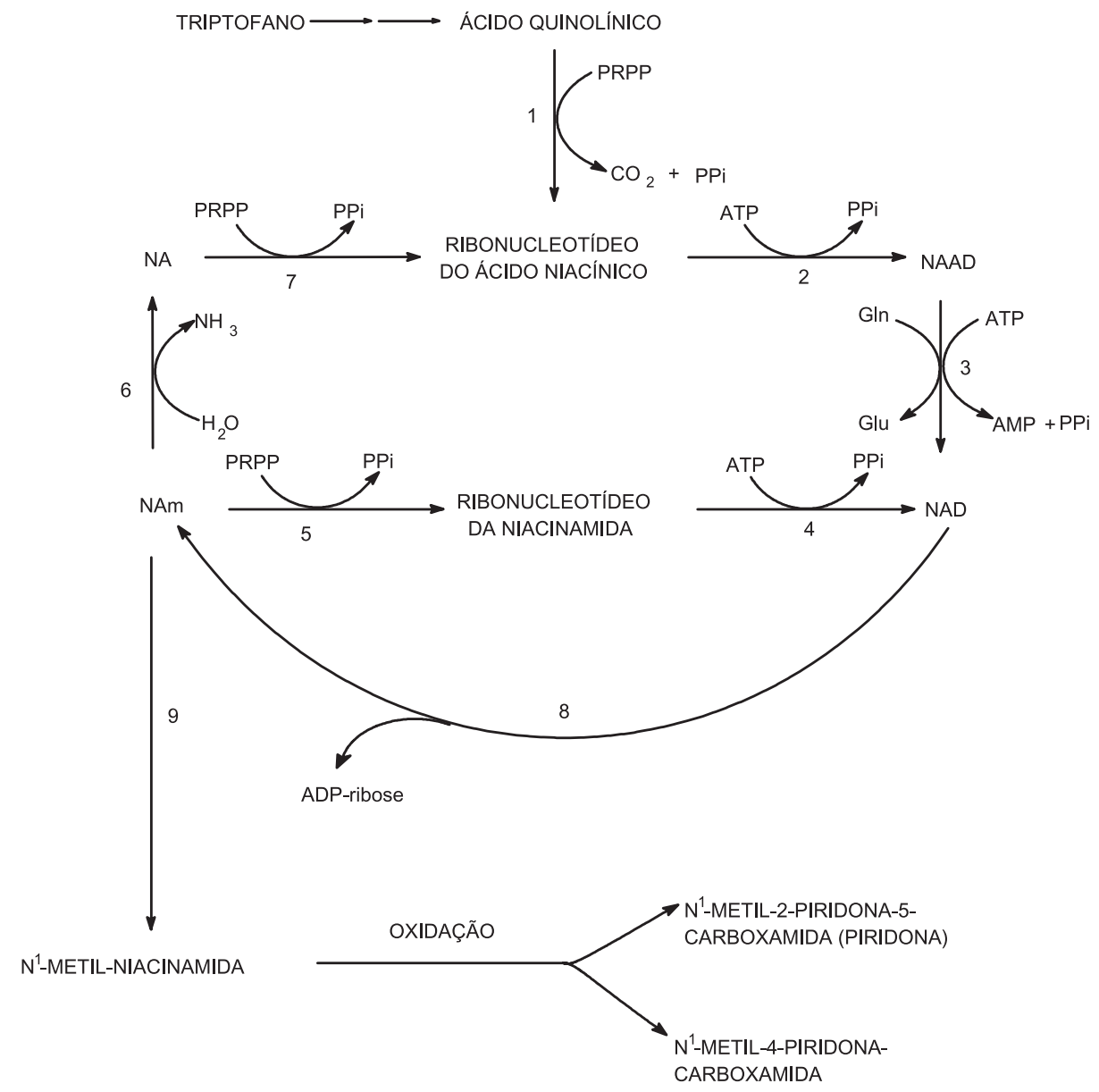

Figura 3. Metabolismo geral da niacina. NA - ácido niacínico; NAM - niacinamida; NAAD - ácido niacínico adenina dinucleotídio; PPPP - fosforribosil pirofosfato. Identificação das enzimas: 1 - quinolinato fosforribosiltransferase; 2 e 4 - adeniltransferases; 3 - NAD sintetase; 5 - niacinamida fosforribosiltransferase; 6 - niacinamida desaminase; 7 - niacinato fosforribosiltransferase; 8 - poli(ADP-ribose) sintetase ou glicohidrolase; 9 - $N^{I}$-metiltransferase 
3-L-hidroxiacil-CoA a $\beta$-cetoacil-CoA. A coenzima NADH, gerada a partir das etapas supracitadas, participa como um carreador de elétrons para a etapa da cadeia transportadora de elétrons, a qual é essencial no metabolismo aeróbio. A coenzima NADPH funciona como um doador de elétrons na biossíntese de ácidos graxos e esteroides e na oxidação da glicose-6-fosfato a ribose-5-fosfato na via pentose fosfato. ${ }^{8,48}$

\section{Sinalização celular}

A coenzima $\mathrm{NAD}^{+}$também é requerida para reações de caráter não redox de suma importância para o metabolismo celular. Ela é usada em reações pós-translacionais de uma variedade de proteínas, particularmente de algumas associadas aos cromossomos. Estes últimos são compostos de DNA, de proteínas histonas e não histonas. As histonas, as quais são distinguidas pelo seu conteúdo elevado de aminoácidos básicos, servem como esqueleto mantendo a estrutura original do DNA. As proteínas não histonas são usadas na regulação da expressão de genes. ${ }^{48}$ A coenzima $\mathrm{NAD}^{+}$é o substrato para três classes de enzimas que clivam a ligação $\beta$ - $N$-glicosílica do $\mathrm{NAD}^{+}$ para niacinamida livre, e catalisam a transferência de (ADP)-ribose. Uma classe de enzimas promove a formação de ADP-ribose cíclica, a qual mobiliza cálcio dos estoques intracelulares em diferentes tipos de células. ${ }^{49} \mathrm{~A}$ ação da ADP-ribose cíclica na célula parece ser similar àquela do 3,4,5-trifosfato de inositol $\left(\mathrm{IP}_{3}\right)$, um importante sinalizador celular formado a partir de metabolização de fosfolipídios de membrana. ${ }^{48,50}$ Já o ácido niacínico adenina dinucleotídeo fosfato $\left(\mathrm{NAADP}^{+}\right)$, formado in vivo pela desaminação de $\mathrm{NADP}^{+}$, também atua como regulador de cálcio celular, porém o mecanismo difere da ação da ADP-ribose cíclica. ${ }^{49,51} \mathrm{Em}$ um estudo, foi sugerido que o receptor rianodina é o canal de cálcio sensível à modulação positiva pelo NAADP. Este mensageiro é um potente agente de mobilização de cálcio em linfócitos T. ${ }^{52}$ Recentemente, dados preliminares indicaram que a inibição da sinalização via $\mathrm{NAADP}^{+}$poderia representar um modo específico e efetivo para modular a ativação de linfócitos T e, portanto, auxiliar na terapia de doenças autoimunes. ${ }^{53}$

Duas outras classes de enzimas catalisam a transferência de ADP-ribose para proteínas: poli-ADP-ribose polimerases (PAPRs) e mono-ADP-ribosiltransferases..$^{50,54}$ As enzimas nucleares PARP catalisam a ligação da ADP-ribose a várias proteínas cromossomiais. Esta modificação pós-translacional é mais complexa do que uma simples metilação ou fosforilação. Uma molécula de niacinamida é descartada em cada evento de ADP-ribosilação. As proteínas poli-ADP-ribosiladas funcionam na replicação e reparo do DNA, bem como em vários processos celulares incluindo diferenciação e apoptose..$^{27,54-56}$ Alguns estudos in vitro e com modelos animais mostraram que agentes oxidantes e carcinógenos químicos, os quais reagem com o ácido desoxirribonucleico (ADN), ativaram as PARPs alterando o metabolismo do ADN e aumentando o consumo de trifosfato de adenosina (ATP). ${ }^{57,58}$ A niacinamida, um produto da atividade da PARP dependente de $\mathrm{NAD}^{+}$, poderia fornecer ação anti-inflamatória como elemento de retroalimentação negativa da enzima PARP-1. Entretanto, a niacinamida exerce efeito anti-inflamatório e antioxidante direto, independente da atividade da PARP. ${ }^{57}$ Já as mono-ADP-ribosil transferases dependentes de NAD ${ }^{+}$ funcionariam como sinalizadores celulares por modulação da atividade da proteína-G. ${ }^{54}$ Recentemente, observou-se que a inibição da formação da poli-ADP-ribose tenderia a causar tumorigênese, porém poderia reduzir a sinalização do processo inflamatório dependente do fator nuclear KappaB. A inibição desta sinalização poderia ser extremamente valiosa no tratamento de condições inflamatórias agudas, tais como, infarto do miocárdio e choque séptico. ${ }^{50}$

A coenzima $\mathrm{NAD}^{+}$também é imprescindível para a atividade de uma família de enzimas denominadas sirtuínas ou reguladores silen- ciosos da informação (SIR). Estas são desacetilases ou ADP-ribosil transferases envolvidas na regulação transcricional, na estabilidade do genoma, na proteção neuronal, na homeostase metabólica e na longevidade. ${ }^{54,59-61}$ A SIR2, uma desacetilase de histona dependente de $\mathrm{NAD}^{+}$, tem recebido bastante atenção por estar envolvida no silenciamento de genes e na longevidade em leveduras. ${ }^{62,63}$ Um homólogo humano da proteína SIR2, a SIRT1, regularia a atividade do supressor p53 e inibiria a apoptose, além de modular muitos aspectos da homeostase lipídica e glicídica em vários tecidos. ${ }^{60,64}$ Segundo um estudo com cultura de leveduras, a extensão do número de divisões celulares em condição de restrição calórica requereu a expressão da SIR2.$^{65} \mathrm{O}$ mais interessante nesse estudo e em outros foi que o inibidor fisiológico, tanto do SIR2 como do SIRT1, foi a niacinamida. ${ }^{63,65}$ Também foi demonstrado que o aumento da expressão do gene PNC1, o qual codifica a enzima niacina desaminase (enzima que desamina a niacinamida), é necessário para longevidade por restrição calórica em leveduras. ${ }^{65}$ Estudos em ratos têm demonstrado a importância das sirtuínas SIRT 3, 4 e 5 no metabolismo energético nas mitocôndrias. ${ }^{62,66,67}$ Animais nocauteados deficientes em SIRT3 exibiram uma grande hiperacetilação de resíduos de lisina de proteínas mitocondriais. ${ }^{66}$ Isto, de certa forma, favoreceria eventos de degeneração mitocondrial e apoptose.

Portanto, a partir de algumas evidências, foi sugerido que a niacina, como $\mathrm{NAD}^{+}$e/ou niacinamida, poderia modular ou regular a homeostase metabólica, a funcionalidade do genoma e processos celulares críticos que afetariam a progressão de doenças degenerativas relacionadas com a idade, tais como, câncer, diabetes e demência. ${ }^{58-60,68}$

\section{Combinação com metais}

A habilidade do ácido niacínico em se combinar com metais poderia explicar algumas de suas interações biológicas com metais essenciais. Em um trabalho científico foi proposto que o ácido niacínico seria parte integrante de um fator de tolerância à glicose, isolado de leveduras. Na realidade, este fator é um complexo orgânico contendo cromo que poderia potencializar a resposta à insulina em alguns indivíduos. ${ }^{69} \mathrm{Já}$ em outro estudo foi observado que a combinação da niacina com o cromo teria um efeito terapêutico contra o estresse oxidativo em diferentes tecidos de ratos hiperlipidêmicos. Particularmente, haveria uma ação protetora na função endotelial via modulação negativa do caminho de sinalização ox-LDL (lipoproteína de baixa densidade oxidada)/LOX-1 (receptor endotelial para LDL oxidada). ${ }^{70}$ Em outro estudo, a suplementação da dieta de ratos e camundongos com ácido niacínico aumentou a biodisponibilidade de zinco e ferro. ${ }^{71}$

\section{AÇÃO FARMACOLÓGICA}

Há cerca de 50 anos atrás o patologista canadense R. Altschul descobriu que o ácido niacínico usado na dosagem de alguns gramas reduzia a colesterolemia. Ele foi o primeiro fármaco oral usado para o tratamento de deslipidemias na clínica médica. ${ }^{72,73} \mathrm{O}$ primeiro estudo científico, intitulado Coronary Drug Project, foi conduzido nos EUA com cerca de 8.000 indivíduos, entre 1966 e 1975, para avaliar a segurança e eficácia a longo prazo de fármacos hipolipemiantes, dentre estes o ácido niacínico. O tratamento com esse ácido apresentou benefício modesto na redução do infarto do miocárdio recorrente não fatal, porém não diminuiu a mortalidade total. ${ }^{74}$ Entretanto, um estudo subsequente, conduzido ao longo de 9 anos após o primeiro estudo, mostrou uma redução significativa na mortalidade em relação ao grupo placebo. ${ }^{74,75}$ Segundo os autores, este efeito benéfico resultou da diminuição dos episódios de infarto 
do miocárdio recorrente não fatal ou do efeito hipocolesterolêmico ou ambos. A aplicação do ácido niacínico em doses farmacológicas de 1-4 $\mathrm{g} \mathrm{dia}^{-1}$ exerce uma variedade de efeitos fisiológicos que melhora o perfil lipídico em pacientes com dislipidemias e disfunção endotelial, reduzindo efeitos aterotrombóticos. ${ }^{76,77} \mathrm{O}$ ácido niacínico reduz o colesterol total, triglicerídeo (triacilglicerol), VLDL (lipoproteína de muito baixa densidade), LDL-colesterol e Lp(a) (lipoproteína (a)), sendo um dos poucos fármacos que efetivamente aumentam a HDL (lipoproteína de alta densidade)-colesterol. ${ }^{12,73,78-80}$ Em contrapartida, seu uso em doses farmacológicas produz uma série de efeitos adversos já mencionados no tópico hipo- e hipervitaminose. Tais efeitos aliados ao desconhecimento da ação da niacina ao nível molecular, bem como o aparecimento de novos fármacos, como exemplo as estatinas, restringiram o uso do ácido niacínico como fármaco.

Os primeiros estudos da ação do ácido niacínico no âmbito molecular apontaram que células em cultura, obtidas do tecido adiposo de ratos, quando tratadas com ácido niacínico, apresentavam inibição da produção de $\mathrm{AMP}_{\mathrm{c}}$ estimulada pela adrenalina. ${ }^{81}$ Esses resultados foram confirmados posteriormente por Aktories e colaboradores, ${ }^{82}$ que sugeriram a presença de um receptor de membrana plasmática para o ácido niacínico e um fármaco congênere o ácido N4-óxi-5metil-pirazina-2-carboxílico (acipimox). O interesse progressivo pelo ácido niacínico ressurgiu a partir da evidência de um receptor específico acoplado à proteína $\mathrm{G}$ com afinidade pelo fármaco. $\mathrm{O}$ suposto receptor foi achado em macrófagos, baço e tecido adiposo. ${ }^{83}$ A partir do uso de agonistas, cobaias mutantes, técnicas de clonagem e PCR (reação em cadeia da polimerase) foi identificado um receptor acoplado a uma proteína Gi (inibitória), denominado HM74A ou GPR109A em humanos e PUMA-G em camundongos. Este se mostrou fortemente expressado em tecido adiposo. Foi postulado que sua ativação causou inibição da adenilato ciclase, queda no teor de $\mathrm{AMP}_{\mathrm{c}}$ e consequente redução na fosforilação da proteína quinase A (PKA). ${ }^{84-88}$ Isso provocaria a inibição de lipases intracelulares, causando redução da hidrólise de triacilglicerois no tecido adiposo. O resultado final seria a redução da quantidade de ácidos graxos não esterificados (ácidos graxos livres) no sangue com concomitante redução na síntese de VLDL, LDL e Lp(a) e aumento na síntese de HDL no fígado. ${ }^{88-90}$ Adicionalmente, o decréscimo de ácidos graxos livres circulantes intervém com a atividade da proteína transferidora de éster de colesterol (CETP), modulando negativamente a proteína inibidora da transferência de lipídios (LTIP). Isso permitiria que a LDL participasse mais ativamente na transferência de ésteres de colesterol para HDL. ${ }^{91}$ Alguns autores têm sugerido que o ácido niacínico não somente afeta a atividade de lipases no tecido adiposo, como também o conteúdo de adipocinas. Estas últimas são uma classe de hormônios (ex., adiponectina e leptina) produzida no tecido adiposo, que desempenha um papel essencial na homeostase de energia, afetando a resistência à insulina, o metabolismo glicídico e lipídico, a ingestão de alimentos e o processo inflamatório. ${ }^{92}$ Em estudos com humanos, verificou-se um aumento considerável no teor de adiponectina após tratamento com ácido niacínico, porém não foram monitoradas as funções ateroprotetivas atribuídas à adiponectina, tais como, ação anti-inflamatória e preservação da função endotelial. Além do mais, houve um aumento da resistência à insulina ${ }^{93}$ Em um estudo recente, foi demonstrado que o ácido niacínico suprime a produção de quemoquinas pró-inflamatórias (ativadores de resposta inflamatória) e aumenta o teor de adiponectina. ${ }^{94}$ Entretanto, o estudo foi in vitro, não sendo possível monitorar a função endotelial.

A ação molecular do ácido niacínico sobre o tecido adiposo é bem estudada, porém insuficiente para explicar a sua ampla ação antilipêmica. Aliás, a redução da degradação de triacilglicerois no tecido adiposo deveria provocar obesidade, mas isso de fato não ocorre já que esse efeito é neutralizado pelo aumento da lipólise, após 24 h do uso do fármaco, no tecido adiposo e, consequentemente, dos teores plasmáticos de ácidos graxos livres. ${ }^{95}$ Aliás, esse ressalto nos teores de ácidos graxos livres poderia, em parte, mediar a resistência à insulina induzida pelo uso prolongado do ácido niacínico. ${ }^{96} \mathrm{Em}$ estudo prévio com voluntários, foi verificada uma redução em $21 \%$ na síntese de triacilglicerois hepáticos com o uso da terapia com ácido niacínico, sugerindo que o fígado é o alvo majoritário do fármaco na regulação da secreção de lipoproteínas (VLDL e LDL) contendo apoproteínas B (apo B). ${ }^{97}$ Observou-se ainda que a adição de ácido niacínico a uma cultura de células hepáticas da linhagem hep G2 aumentou a degradação intracelular de apo B, que foi seguida de uma redução da sua secreção. ${ }^{98}$ Em estudos subsequentes, foi descrito que o ácido niacínico inibiu, de forma não competitiva, a enzima diacilglicerol aciltransferase-2 (DGAT2) presente na fração microssomial hepática, a qual catalisa a reação final da via metabólica de síntese de triacilglicerois. A inibição dessa enzima diminuiria a síntese de triacilglicerois e a formação da VLDL, resultando no aumento da degradação hepática de apo B. Haveria então uma redução no número de partículas da VLDL e de seu catabólito, a LDL, o que explicaria os teores mais baixos de apo B e LDL observados, na clínica, após o uso terapêutico do ácido niacínico. Adicionalmente, a inibição da DGAT2, particularmente, diminuiria a concentração de VLDL1, que é mais rica em triacilglicerois, o que resultaria na redução da concentração das partículas de LDL pequenas e densas (sd-LDL) ${ }^{95,99,100}$ As partículas de sd-LDL, a despeito do seu menor teor de colesterol, parecem ser mais aterogênicas do que as partículas maiores de LDL. A sd-LDL teria maior habilidade para atravessar a parede arterial, bem como possuiria uma maior meia-vida no plasma. ${ }^{101}$

Alguns estudos prévios com plasma de humanos indicaram que a niacina diminuiu o catabolismo, de forma geral, da HDL-apo A sem alterar a taxa de síntese da apo A. ${ }^{102}$ Em outro trabalho, a adição de ácido niacínico a uma cultura de células hepáticas da linhagem hep G2 inibiu seletivamente a captação de subfrações da HDL plasmática, rica em apo A-I (HDL-apo A-I), porém não afetou as das outras subfrações da HDL ricas em éster de colesterol (HDL-apo A-I + A-II). Além disso, não alterou a síntese de novo da apo A-I nessa cultura de células. ${ }^{103}$ É importante ressaltar que as subfrações da HDL-apo A-I são mais eficientes no transporte de colesterol reverso, ou seja, na retirada de colesterol das lipoproteínas aterogênicas com apo-B e dos macrófagos presentes no endotélio. Teores elevados de HDLapo A-I estão associados intimamente com menor risco de doença coronariana. ${ }^{104}$ Também com o uso das células hep G2 em cultura, foi possível observar a menor expressão, na superfície dessas células, da $\beta$-cadeia da adenosina trifosfato sintase. A ação dessa enzima é um passo importante na via de captação de subfrações da HDL-apo A-I para catabolismo hepático. Contudo, isso não afetou os eventos mediados pelo receptor BI, o qual é seletivo para captação de subfrações da HDL-apo A-I + A-II. ${ }^{105}$ Dessa forma, existem fortes indícios de que o ácido niacínico iniba seletivamente a remoção de subfrações da HDLapo A-I plasmática, através da redução da atividade da adenosina trifosfato sintase hepática, porém não afeta a captação de subfrações da HDL-apo A-I + A-II e nem mesmo afeta a síntese de apo A-I. Isso resultaria na retenção de subfrações da HDL-apo A-I por mais tempo na corrente sanguínea, possibilitando uma ação mais efetiva do sistema de transporte reverso de colesterol. ${ }^{95,100}$ Por outro lado, o ácido niacínico poderia promover o efluxo de colesterol de adipócitos, ${ }^{106}$ monócitos e macrófagos ${ }^{107}$ para HDL-apo A-I, através do aumento da expressão dos receptores ativados por proliferador de peroxissomo (PPAR $\gamma$ ), de receptores LXR $\alpha$ e da proteína transportadora ABCA1 que está envolvida primariamente no transporte reverso de colesterol. De algum modo, o caminho PPAR $\gamma$-LXR $\alpha$-ABCA1 poderia ser um mecanismo adicional no qual o ácido niacínico aumentaria os teores plasmáticos de subfrações da HDL-apo A-I. ${ }^{106}$ Os PPAR $\gamma$ são um 
grupo de proteínas receptoras nucleares que funcionam como fatores de transcrição, desempenhando um papel essencial na regulação da diferenciação celular, desenvolvimento, metabolismo (glicídios, lipídios e protídios) e carcinogênese em organismos superiores. ${ }^{108}$ Propos-se recentemente que o ácido niacínico exibe propriedades anti-inflamatórias e antioxidativas em células endoteliais, além do seu efeito antilipêmico. A partir do uso de células endoteliais da aorta humana, em um modelo in vitro, foi observada uma redução nas espécies reativas do oxigênio (EROs), bem como de citocinas próinflamatórias, como exemplo o fator de necrose tumoral- $\alpha$ (FNT- $\alpha$ ), e de moléculas de adesão. Também houve uma redução na oxidação da LDL e da adesão de monócitos e macrófagos às células endoteliais, eventos chaves na fase inicial da aterogênese. Dessa forma, o ácido niacínico aumentaria o potencial redox do endotélio vascular, resultando na inibição do estresse oxidativo e de genes envolvidos no processo de inflamação endotelial. ${ }^{95,99,100}$ Esses resultados são sugestivos de que o efeito antiaterosclerótico do ácido niacínico não se limita a sua ação antilipêmica, mas também a efeitos anti-inflamatórios e antioxidativos na região endotelial de vasos sanguíneos.

A ligação do ácido niacínico ao receptor HM74A é, possivelmente, um mecanismo secundário na modulação da síntese e da secreção hepática de lipoproteínas contendo apo B. Entretanto, o estudo desse receptor auxilia na identificação de possíveis fármacos com ação hipolipemiante; é importante para estudar os efeitos adversos imputados ao ácido niacínico e, sobretudo, para entender sua ação anti-inflamatória a nível vascular. Outro subtipo de receptor foi identificado e denominado como HM74 ou GPR109B, porém sua afinidade pelo ácido niacínico foi muito baixa ${ }^{84,87}$ A comparação da sequência de nucleotídeos do HM74 e HM74A mostrou que esse último é uma versão reduzida do HM74, com 24 resíduos de aminoácidos a menos na região C-terminal ${ }^{84} \mathrm{~A}$ investigação da estrutura do receptor HM74A, através de estudos com mutagênese, indicou algumas regiões críticas para a ligação do ácido niacínico: resíduos de asparagina 86/triptofano 91 (hélice transmembrana 2 (laço extracelular 1), arginina 111 (hélice transmembrana 3), serina 178 (laço extracelular 2), fenilalanina 276/tirosina 284 (hélice transmembrana 7). ${ }^{88,90}$ A presença e a distribuição do grupo carboxílico é essencial para ativação do receptor, já que a niacinamida é incapaz de ativá-lo e o ácido 3-(3-piridina)-propiônico e o ácido 3-piridina-acético tiveram ação muito limitada. A substituição do ácido niacínico com grupo metila só foi tolerada na posição 5 ou 6 . A oxidação do heteroátomo do anel piridínico diminuiu consideravelmente a afinidade pelo receptor. Os compostos heterocíclicos com estruturas similares ao ácido niacínico apresentaram maior ou menor afinidade pelo receptor, conforme a posição e o tipo de substituinte. Alguns compostos químicos classificados por ordem decrescente de afinidade foram: ácido niacínico > ácido piridazina-4-carboxílico > ácido pirazol-3carboxílico > ácido furano-3-carboxílico. O ácido metil-pirazina2-carboxílico e o acipimox também foram agonistas potentes, ${ }^{83}$ sendo o último usado na clínica médica atualmente. Uma série de outros agonistas do receptor HM74A tem sido identificada recentemente, como segue: os pirazois e seus derivativos ${ }^{109,110}$ e derivados da ureia. ${ }^{111} \mathrm{O}$ ácido 4,5-di-hidro-5-metil-4-óxo-5fenil-2-furano-carboxílico, cujo nome comercial é acifran, e seus análogos foram agonistas potentes do mesmo receptor, causando a redução da fosforilação de proteínas quinases ativadas por mitógeno (ERK1/ERK2). ${ }^{112}$ Recentemente, o agonista denominado MK-0354 foi testado em estudo de fase 2, com o intuito de disparar os supostos efeitos antilipêmicos, mediados pelo receptor HM74A, sem provocar efeitos adversos. O agonista não causou eventos de ruborização, porém não afetou positivamente o perfil lipídico. Nesse estudo, é sugerido que o HM74A não é o único receptor responsável pelos efeitos do ácido niacínico na modulação lipídica. ${ }^{113} \mathrm{Na}$ concepção dos autores dessa revisão, o baixo efeito antilipêmico do MK-0354 poderia advir do fato deste agonista, a princípio, não modular a síntese de lipoproteínas e de triacilglicerol hepático. Em menor escala, alguns agonistas seletivos do receptor HM74 foram descritos, como segue: ácido 1-alquil-benzotriazol5-carboxílico e seus derivados, ${ }^{114}$ ácido 3-nitro-4-amino-benzoico e ácido 6-amino-niacínico. ${ }^{109}$

O uso da técnica de PCR possibilitou estudar a distribuição do receptor HM74A em humanos. ${ }^{85}$ A expressão deste receptor foi detectada em tecido adiposo, pulmão, baço e traqueia, sendo similar aos resultados obtidos por Wise e colaboradores ${ }^{84} \mathrm{~A}$ presença de HM74A também foi proposta em macrófagos e células de Langerhans da epiderme. Sua ativação poderia explicar a manifestação de ruborização provocada pelo uso farmacológico do ácido niacínico. Embora a ruborização não seja nociva e desapareça com o uso continuado do fármaco, esta é a principal causa de abandono do tratamento. ${ }^{89,115}$ Esses autores conduziram um estudo elegante com ratos nocauteados, sem HM74A ou sem receptores de prostaglandinas $\mathrm{D}(2)$ e $\mathrm{E}(2)$ (PGD(2) e PGE(2)), indicando a ausência de ruborização induzida por ácido niacínico. A associação entre a liberação de PG no tecido cutâneo e a ruborização induzida por ácido niacínico foi proposta inicialmente no final da década de $80 .{ }^{116}$ Outros autores também associaram a ativação do receptor HM74A a um aumento do caminho de sinalização do ácido araquidônico, de modo que o uso de antagonistas do receptor (1) da PGD(2) suprimiu a ruborização. ${ }^{117}$ Junto com o receptor (1), também é ativado o receptor (2) pela PGE(2) e o receptor 4 pela PGE(4) nos capilares, induzindo a vasodilatação cutânea. ${ }^{100,117}$ De fato, uma compilação de dados da literatura corroborou que fármacos anti-inflamatórios não esteroides (ex., aspirina) e antagonistas do receptor de PGD(2) (ex. laropiprant) podem mitigar o sintoma de ruborização. ${ }^{73,118} \mathrm{Al}$ guns autores têm demonstrado, em modelo animal, que o eritema e o aumento de temperatura local que acompanha a ruborização seriam causados pela liberação da serotonina de plaquetas, após a vasodilatação e o aumento da permeabilidade capilar. $\mathrm{O}$ uso de antagonista dos receptores de serotonina $\mathrm{H}(1)$ e $2 \mathrm{~A}$ inibiu o aumento da temperatura local, induzido pelo ácido niacínico. Foi concluído que ambos, PG e serotonina, são responsáveis pela ruborização induzida por esse ácido. ${ }^{119}$ Os flavonoides quercetina e luteolina foram capazes de eliminar a ruborização, em cobaias, causada pela ação da PGD(2) induzida por ácido niacínico e de reduzir a liberação da serotonina de plaquetas. ${ }^{119,120}$ Uma revisão crítica recente sobre a contribuição do metabolismo das prostaglandinas para a saúde da parede vascular sugere que alguns dos efeitos benéficos da niacina poderiam resultar na ativação dos mesmos caminhos metabólicos responsáveis pelos efeitos adversos. Dessa forma, foi concluído que o uso de antagonistas do receptor de PGD(2) e PGE deve ser visto com cautela, já que a vasodilatação dos vasos periféricos poderia ser crucial para a ação aterotrombótica do ácido niacínico. ${ }^{121} \mathrm{~A}$ ativação dos receptores HM74 e HM74A pelo ácido niacínico, em macrófagos, além de ativar a síntese de prostaglandinas também induziu a ativação dos fatores de transcrição PPAR $\gamma$. Essa indução poderia ser a base de um novo mecanismo para ruborização mediada pelo ácido niacínico. ${ }^{122}$

Alguns estudos foram publicados relacionando o uso de doses farmacológicas de niacina com esquizofrenia, doença renal e diabetes tipo 2. O uso de ácido niacínico no quadro de esquizofrenia remonta a algumas décadas atrás, quando se observou algumas semelhanças com o quadro psiquiátrico da pelagra. Uma terapia controversa para esquizofrenia, baseada em vitaminas, recebeu o nome de psiquiatria ortomolecular. ${ }^{123}$ Estudos científicos, baseados em ensaios controlados com placebo, não foram capazes de corroborar a eficácia da 
terapia com niacina. ${ }^{124} \mathrm{~A}$ administração de ácido niacínico melhorou o metabolismo lipídico renal e, portanto, a função renal em pacientes com falência renal crônica. A perda progressiva da função renal em pacientes com doença renal é acompanhada por hipertensão, estresse oxidativo, inflamação e dislipidemia. O ácido niacínico atenuou todos esses eventos reduzindo a ativação de fatores de transcrição, como o FNT-K $\beta$, que estimulam o quadro inflamatório, e agindo como fármaco antilipêmico. ${ }^{125}$ Alguns estudos foram conduzidos na tentativa de relacionar o uso do ácido niacínico com o quadro de diabetes. Entretanto, os dados são conflituosos, ora ele tem uma ação positiva, ora negativa. ${ }^{22,126} \mathrm{O}$ cromo ligado à niacina poderia melhorar o quadro de diabetes tipo $2,{ }^{127}$ enquanto a niacinamida ou o ácido niacínico livre poderiam piorar o quadro de resistência à insulina. ${ }^{128} \mathrm{~A}$ conjugação do ácido niacínico com estatinas tem mostrado efeitos positivos sobre as dislipidemias aterogênicas, como será discutido mais à frente. Porém, o efeito dessa combinação sobre a sensibilidade à insulina ainda não é bem conhecido. ${ }^{129}$ Portanto, a exposição por longo tempo ao ácido niacínico isolado ou conjugado deve ser monitorada em pacientes com quadro diabético ou com baixa tolerância à glicose.

O emprego do ácido niacínico como fármaco está disponível em três formulações: a de ação imediata, a de ação intermediária ou extendida (NE) e a de ação lenta, as quais diferem em sua eficácia e segurança. Existe uma grande confusão na designação dos diferentes tipos de formulações, particularmente no que diz respeito às formulações de ação intermediária e lenta. Aqui trataremos as três como formulações independentes. O ácido niacínico de ação imediata é rapidamente absorvido e excretado e atinge valores máximos no plasma cerca de 30 a 60 min após sua ingestão. Sua meia vida metabólica é de $1 \mathrm{~h}$ e geralmente é prescrito em doses múltiplas. O ácido niacínico de liberação lenta, também conhecido como de liberação controlada ou sustentada, apresenta tempo de absorção geralmente maior que $12 \mathrm{~h}$. O ácido niacínico de formulação NE é absorvido num período de 8 a $12 \mathrm{~h}$, sendo ingerido uma vez ao dia. Embora a formulação de ação lenta não cause ruborização, ela é capaz de causar insuficiência hepática. $\mathrm{O}$ ácido niacínico é metabolizado por duas vias metabólicas: a via no qual é conjugado com a glicina para formação do ácido niacinúrico e a via que abrange uma série de reações de óxido-redução que forma a niacinamida e derivados pirimidínicos. ${ }^{76} \mathrm{~A}$ formulação de ação lenta induz a via de conversão à niacinamida, que favorece a formação de dois catabólitos: $\mathrm{N}^{1}$-metilniacinamida e 2-piridona. O último catabólito é formado a partir da reação de óxido-redução catalisada pela enzima aldeído oxidase. ${ }^{130}$ Há pouco conhecimento ainda sobre quais os mecanismos que podem estar envolvidos no caso de hepatotoxicidade originada pelo uso de antilipêmicos. ${ }^{12,131}$ Os autores deste artigo de revisão sugerem que a ativação acentuada da via de conversão da niacinamida poderia causar um desequilíbrio no estado redox, provocando estresse oxidativo, e/ou causar a espoliação da SAM hepática. A presença de EROs levaria à lise de hepatócitos, o que desencadearia um aumento nas transaminases séricas. Aliás, o estresse oxidativo é um dos mecanismos gerais propostos para o quadro de dano hepatocelular induzido por medicamentos. ${ }^{132} \mathrm{O}$ SAM é uma espécie de doador universal de grupamento metila para proteínas em reações pós-translacionais, na neutralização de xenobióticos (substâncias estranhas ao organismo, que não são produzidas normalmente ou não se espera que estejam presentes) e na síntese de colina (um constituinte dos fosfolipídios de membrana). ${ }^{133} \mathrm{~A}$ redução do teor de SAM na célula poderia afetar a funcionalidade da membrana causando apoptose. O uso da niacina de liberação imediata é limitado pela alta taxa de efeitos colaterais (10-50\% dos casos de interrupção do tratamento): rubor, calor, prurido, náusea, dispepsia, dor abdominal, diarreia e hiperuricemia. A ruborização ocorre alguns minutos após o uso da formulação de ação imediata, porque o ácido niacínico em grande quantidade satura a via da niacinamida e passa, então, a ser convertido a ácido niacinúrico, que dispara a produção de PGs. ${ }^{12,76}$ Os autores desse artigo de revisão sugerem que o aumento da excreção urinária do ácido niacinúrico reduz a capacidade do sistema renal para excretar o ácido úrico. Aliás, fato parecido ocorre quando o excesso de etanol aumenta a hiperlacticacidemia, ou seja, excesso de ácido láctico no sangue, que também supostamente seria a causa da hiperuricemia em alcoólatras. ${ }^{134} \mathrm{~A}$ formulação NE tem mostrado vantagens em relação às outras duas porque somente necessita ser tomada uma vez ao dia e provoca menos efeitos colaterais. ${ }^{21,76}$ Segundo alguns autores essa formulação é bem tolerada, apenas produzindo episódios leves ou moderados de ruborização. ${ }^{135,136} \mathrm{~A} \mathrm{NE}$, comercializada como niaspan, é a única formulação aprovada pela Food and Drug Administration (FDA) para tratamento das dislipidemias. ${ }^{12}$ Alguns estudos foram feitos para avaliar a eficácia e os efeitos colaterais do niaspan com posologia de uma dose oral diária. Foi sugerido que o niaspan maximiza os benefícios do ácido niacínico sem afetar o controle glicêmico e sem produzir ruborização apreciável. O niaspan produziria menos hepatotoxicidade do que formulações anteriores da niacina. ${ }^{137}$ Outros autores também sugeriram que o niaspan é um fármaco bem tolerado. ${ }^{138,139}$ Aliás, Vogt e colaboradores ${ }^{138}$ mostraram que o niaspan é seguro e bem tolerado, quando realizaram um estudo multicêntrico (estudo feito em laboratórios independentes usando o mesmo protocolo) em pacientes alemães com alto risco de doença coronariana devida à HDL baixa. Por outro lado, um quadro de hepatotoxicidade, inclusive com aumento das transaminases séricas em mais de três vezes o valor de referência, foi observado com um consumo de somente $750 \mathrm{mg} \mathrm{dia}^{-1}$ de ácido niacínico em menos de 3 meses. ${ }^{140} \mathrm{~A}$ combinação do ácido niacínico com o laropiprant, um antagonista do receptor PGD(2), poderia reduzir, em parte, o efeito de ruborização, permitindo assim que o ácido niacínico pudesse ser usado em doses maiores. Essa combinação só foi recomendada para pacientes de alto risco que não obtiveram êxito com o uso de estatinas. ${ }^{141}$ Enquanto o tratamento de diabéticos com ácido nacínico de ação imediata prejudicou o controle da glicose, o uso da formulação $\mathrm{NE}\left(1,0-1,5 \mathrm{~g} \mathrm{dia}^{-1}\right)$ em pacientes com diabetes do tipo 2 favoreceu o tratamento da dislipidemia sem afetar o controle glicêmico. ${ }^{142}$ Por outro lado, algumas evidências indicam que doses farmacológicas de niacinamida retardam a disfunção das células $\beta$-pancreáticas e o avanço do diabetes tipo $1,{ }^{128}$ porém esta ação não tem sido bem estabelecida em ensaios clínicos. ${ }^{5}$

A combinação do ácido niacínico com diferentes antilipêmicos tem mostrado ação sinergística potente, representando um novo agente efetivo no combate às deslipidemias. Os primeiros estudos foram conduzidos por Blankenhorn e colaboradores ${ }^{143} \mathrm{com}$ ácido niacínico associado ao colestipol, um tipo de resina que reduz a reabsorção de ácidos biliares via circulação entero-hepática, mobilizando assim o colesterol hepático para síntese de mais ácidos biliares. O estudo prospectivo, denominado estudo da aterosclerose em condição de colesterol baixo (CLAS 1), com homens não fumantes e entre 50-60 anos, submetidos previamente à revascularização cirúrgica das coronárias, mostrou a eficácia da combinação de fármacos na regressão do quadro aterosclerótico em um grupo, quando comparado a outro que recebeu placebo. ${ }^{143} \mathrm{Um}$ segundo estudo (CLAS 2) mostrou que, mesmo após 4 anos, pacientes tratados com a combinação apresentaram significativamente menor reincidência no quadro aterosclerótico. Foi concluído que pacientes com revascularização cirúrgica das coronárias devem submeter-se à terapia antilipêmica por longo tempo. ${ }^{144}$ Uma limitação importante nesses estudos prospectivos foi a ausência de um protocolo para comparação da eficácia da combinação dos fármacos em relação aos mesmos usados isoladamente. 
O uso combinado de ácido niacínico e estatinas (ex., lovastatina, sinvastatina, atorvastatina) também foi testado em diversos estudos conduzidos nos últimos 20 anos. Enquanto o ácido niacínico teria a vantagem de reduzir ambas, a síntese hepática da apo B aterogênica e a remoção das partículas apo A-I antiaterogênicas, as estatinas aumentariam tanto a remoção de partículas apo B como também a produção hepática de apo A-I. A princípio, foi testada a combinação $\mathrm{NE}$ /lovastatina (fármaco conhecido como Advicor) na proporção de 2000/40 mg e com uma única dose diária. Após os voluntários serem tratados até 1 ano com a combinação, houve uma queda de 45, 42 e $25 \%$ nos teores de LDL, triacilglicerol e Lp(a) plasmáticos e um aumento de $41 \%$ na HDL. ${ }^{145}$ É bom frisar que o Advicor tem seu uso aprovado pela FDA. Alguns outros estudos comprovaram a eficácia da associação do ácido niacínico com estatina no tratamento de deslipidemias em pacientes com e sem doença coronariana. ${ }^{135,146,147} \mathrm{Em}$ outro estudo, foi usada a combinação NE/lovastatina na proporção de 2000/40 mg em dose única, a qual foi comparada à monoterapia com sinvastatina ou atorvastatina. Após 12 semanas, a combinação foi mais efetiva na redução da LDL do que a sinvastatina a $20 \mathrm{mg}$, sendo, também, mais efetiva no aumento da HDL em comparação à atorvastatina a $10 \mathrm{mg}$ e à sinvastatina a $20 \mathrm{mg} .{ }^{148}$ Essa combinação também foi mais efetiva em reduzir as partículas de sd-LDL em comparação à monoterapia com atorvastatina ou sinvastatina. ${ }^{149}$ Estudos multicêntricos conduzidos com pacientes da Holanda ${ }^{139} \mathrm{e}$ da Índia ${ }^{150}$ também indicaram que a combinação NE/estatina era bem tolerada, segura e eficiente no tratamento de dislipidemias. $\mathrm{O}$ tratamento de dislipidemia aterogênica com NE/sinvastatina, em pacientes com doença coronariana, produziu resultados benéficos no que tange à progressão da estenose, independente do paciente ter resistência à insulina ou síndrome metabólica (designação atribuída a um conjunto de fatores de risco, como hipertensão, hiperglicemia, dislipidemia, obesidade, que condicionam a um grande aumento do risco de desenvolver aterosclerose). ${ }^{151}$ Em outro estudo, foi verificado o efeito do fator tempo de tratamento nos resultados clínicos com o uso da associação ácido niacínico/lovastatina e a monoterapia com estatina. O esquema adotado foi o seguinte: a associação na dose única de 500/20 mg durante 4 semanas; após, a dose foi para 1000/40 mg por 4 semanas e depois foi aumentada para 2000/40 mg. Já para a atorvastatina ou sinvastatina foi usada uma dose única de $10 \mathrm{mg}$ durante 8 semanas, que depois foi aumentada para $40 \mathrm{mg}$. Observou-se que $50 \%$ dos pacientes alcançaram teores adequados de HDL e LDL após 7 semanas com a associação ou a atorvastatina sozinha, enquanto no caso da monoterapia com sinvastatina o mesmo resultado foi alcançado somente após 13 semanas. Essas diferenças indicam que o tempo de tratamento é uma variável de grande relevância na redução do risco de doença coronariana. ${ }^{152}$ Uma série de estudos foi produzida por Taylor e colaboradores ${ }^{147,153-155}$ para avaliar a progressão da aterosclerose em pacientes com diagnóstico de doença coronariana e HDL baixa. No primeiro estudo com duplo cego, (tanto os pacientes como os pesquisadores não sabiam que grupo recebeu a combinação farmacológica) a terapia com NE/estatina retardou a progressão da aterosclerose, após 12 meses de tratamento, medida através da redução do espessamento das camadas íntima e média da carótida. ${ }^{147}$ No segundo estudo, após 24 meses de tratamento, os resultados foram similares ao anterior. Entretanto, neste estudo o desenho experimental foi aberto, ou seja, ambos pesquisadores e pacientes sabiam quem havia recebido a combinação, o que os próprios autores consideraram uma limitação. ${ }^{153}$ Uma reavaliação do primeiro estudo indicou que o aumento da HDL foi acompanhado pela redução do espessamento da carótida tanto em pacientes normoglicêmicos como também naqueles com diabetes. ${ }^{154} \mathrm{Na}$ fase final do estudo, os autores demonstraram que a associação do ácido niacínico com estatina foi muito mais eficiente na redução do espessamento da carótida em comparação à ezetimiba/estatina. ${ }^{155,156}$ A ezetimiba é um potente inibidor da acyl-CoA:colesterol acyltransferase, a qual é uma enzima chave no processo de absorção do colesterol pelos enterócitos. ${ }^{157} \mathrm{~A}$ associação ezetimiba/sinvastatina, adicionada de NE, foi testada em 2 ensaios clínicos com duplo cego. No primeiro, o ensaio foi realizado em 1.220 pacientes com hiperlipidemia dos tipos IIa (somente hipercolesterolemia) ou IIb (hipercolesterolemia com hipertrigliceridemia), durante 24 semanas, com o seguinte protocolo: ezetimiba/sinvastatina $\left(10 / 20 \mathrm{mg} \mathrm{dia}^{-1}\right)$ mais NE (2 g $\left.\mathrm{dia}^{-1}\right)$ ou ezetimiba/sinvastatina $\left(10 / 20 \mathrm{mg} \mathrm{dia}^{-1}\right)$ ou NE $\left(2 \mathrm{~g} \mathrm{dia}^{-1}\right)$. A terapia ezetimiba/sinvastatina mais NE foi mais eficaz em reverter o quadro de deslipidemia do que as outras duas formulações. ${ }^{158}$ No segundo, 942 pacientes foram tratados com ezetimiba/sinvastatina (10/20 $\left.\mathrm{mg} \mathrm{dia}^{-1}\right)$ mais NE (2 $\left.\mathrm{g} \mathrm{dia}^{-1}\right)$ ou ezetimiba/sinvastatina (10/20 $\left.\mathrm{mg} \operatorname{dia}^{-1}\right)$ durante 64 semanas. Outra formulação contendo NE (2 $\left.\mathrm{g} \mathrm{dia}^{-1}\right)$ foi usada por 24 semanas, em seguida, sendo substituída por ezetimiba/sinvastatina $\left(10 / 20 \mathrm{mg} \mathrm{dia}^{-1}\right)$ mais NE $\left(2 \mathrm{~g} \mathrm{dia}^{-1}\right)$ ou ezetimiba/sinvastatina $\left(10 / 20 \mathrm{mg} \mathrm{dia}^{-1}\right)$ por mais 40 semanas. Concluiu-se que a associação ezetimiba/sinvastatina mais NE foi bem tolerada e melhorou significativamente o quadro de deslipidemia, quando comparada à formulação sem NE. ${ }^{136}$ Outro cenário para proporcionar maior proteção cardiovascular seria o uso de antioxidantes naturais (vitaminas $\mathrm{C}, \mathrm{E}, \beta$-caroteno e selênio) como coadjuvantes de fármacos antilipêmicos. Nesse caso, pacientes com HDL baixa poderiam se beneficiar desses antioxidantes, através da redução da oxidação da LDL. Um estudo foi proposto para monitorar, durante 12 meses, o perfil de lipoproteínas em 153 pacientes com doença coronariana submetidos a uma das quatro terapias: ácido niacínico/sinvastatina, ácido niacínico/sinvastatina mais antioxidantes (vitaminas C, E, $\beta$-caroteno, selênio), antioxidantes e placebo. A formulação ácido niacínico/sinvastatina aumentou consistentemente o teor de apo A-I e o tamanho das partículas de HDL, fato não observado, por causa desconhecida, na formulação contendo fármacos antilipêmicos mais antioxidantes. ${ }^{159}$ Outro estudo chegou às mesmas conclusões do trabalho anterior, concluindo que esses suplementos antioxidantes não devem ser recomendados em combinação com fármacos antilipêmicos ou mesmo sozinhos, como terapia para proteção do sistema cardiovascular. ${ }^{160}$

De tudo o que foi apresentado no último parágrafo, é possível inferir que há fortes evidências favoráveis para o uso de NE em conjunto com outros fármacos antilipêmicos, porém faltam mais estudos clínicos de longa duração a fim de se avaliar as taxas de morbidade e mortalidade que informarão se a combinação, de fato, reduz eventos de vasculopatias ateroscleróticas a longo prazo (Tabela 1).

\section{CONCLUSÃO}

A deficiência de niacina dietética e o uso farmacológico de ácido niacínico ou niacinamida têm efeitos dramáticos sobre a homeostase metabólica, a regulação do DNA, a sinalização celular, a função tecidual e, portanto, sobre a saúde. Estudos recentes têm indicado que as sirtuínas, desacetilases dependentes de $\mathrm{NAD}^{+}$, estariam envolvidas na promoção da longevidade observada em uma variedade de seres vivos submetidos à restrição calórica.

O ácido niacínico, em doses farmacológicas, modula favoravelmente a colesterolemia reduzindo a síntese de VLDL, sd-LDL e Lp(a) e aumentando a de HDL. A ação antilipêmica sistêmica do ácido niacínico ocorreria majoritariamente no fígado e estaria relacionada aos seguintes efeitos: 1) inibição da DGAT2, resultando na diminuição da síntese de triacilglicerois e dos teores de lipoproteínas contendo apo-B; 2) diminuição da expressão, na superfície de células hepáticas, da $\beta$-cadeia da adenosina trifosfato sintase, resultando na 
Tabela 1. Ação farmacológica do ácido niacínico e seus principais sítios de ação

\begin{tabular}{llll}
\hline Sítio de ação & Receptor/enzima & Ação primária & Efeito clínico \\
\hline Tecido adiposo & $\begin{array}{l}\text { Indução do receptor HM74A em } \\
\text { adipócitos }\end{array}$ & $\begin{array}{l}\text { Inibição da adenilato ciclase via ativação da pro- } \\
\text { teína Gi; aumento da CETP? }\end{array}$ & $\begin{array}{l}\text { Redução da lipólise; aumento da adiponectina, } \\
\text { do caminho PPAR } \gamma \text {-LXR } \alpha \text {-ABCA1 e do efluxo } \\
\text { de colesterol para HDL-apo A-I? }\end{array}$
\end{tabular}

Fígado artéria

Inibição da DGAT2; redução da atividade da adenosina trifosfato sintase em hepatócitos

Diminuição da síntese de triacilglicerol e do catabolismo apo A-I, aumento do catabolismo da apo B

Redução das EROs, das citocinas pró-inflamatórias e da adesão de monócitos e macrófagos

Tecido epitelial Indução do receptor HM74A em macrófagos e células de "Langerhans"
Inibição de genes ligados à inflamação endotelial; diminuição do estresse oxidativo e da LDL oxidada

Aumento da liberação de PGD(2), PGE(2), PGE(4)
Diminuição da VLDL, da sd-LDL, Lp(a); aumento da HDL-apo A-I

Diminuição da inflamação vascular e da formação de placa lipídica?

Receptor HM74A - receptor identificado em diferentes tipos celulares humanos que é induzido por megadoses de ácido niacínico; Proteína Gi - proteína G inibitória; CETP - proteína transferidora de éster de colesterol; PPAR $\gamma$-LXR $\alpha$-ABCA1- receptores ativados por proliferador de peroxissomo - receptores LXR $\alpha$ -proteína transportadora ABCA1; DGAT2 - diacilglicerol aciltransferase -2; HDL-apo A-I - lipoproteína de alta densidade - apoproteína A-I; VLDL - lipoproteína de muito baixa densidade; Lp(a) - lipoproteína (a); LDL - lipoproteína de baixa intensidade; sd-LDL - LDL pequena e densa; PG - prostaglandinas.

diminuição do catabolismo da HDL-apo A-I que é a subfração mais eficiente no transporte reverso de colesterol. O receptor HM74A, acoplado a uma proteína $\mathrm{Gi}$, tem alta afinidade pelo ácido niacínico e sua ativação seria responsável pela liberação de PGs e serotonina no tecido cutâneo, o que causaria ruborização.

O ácido niacínico é comercializado em 3 formulações: a de ação rápida, a de ação lenta e a NE. A primeira estimula a ruborização, a segunda causa dano hepático e a terceira apresenta uma redução nos efeitos colaterais e, portanto, é a mais bem tolerada. Existem evidências fortes quanto à sinergia entre a combinação NE/estatinas na proteção do sistema cardiovascular de pacientes com HDL baixa, com ou sem história de vasculopatias ateroscleróticas. Um resumo da ação farmacológica do ácido niacínico e seus sítios de ação é apresentado na Tabela 1 .

\section{REFERÊNCIAS}

1. http://pt.wikilingue.com/es/Vitamina_B3, acessada em Outubro 2010.

2. Pietrzik, K.; Dierkes, J. Em The Scientific Basis for Vitamin Intake in Human Nutrition; Walter, P., ed.; Karger: Basel, 1995.

3. van Eys, J. Em Handbook of Vitamins; Machlin, L. J., ed.; Marcel Dekker: New York, 1991.

4. Berdanier, C. D. Em Advanced Nutrition Micronutrients; Wolinsky, I., ed.; CRC Press: Florida, 1998, cap. 4.

5. Jacob, R. A. Em Present Knowledge in Nutrition; Bowman, B. A.; Russell, R. M., eds.; International Life Sciences Institute: Washington, 2006 , cap. 20.

6. Fennema, O. R. Em Food Chemistry; Fennema, O. R., ed.; Marcel Dekker: New York, 1996.

7. Mason, J. B.; Gibson, N.; Kodicek, E.; Br. J. Nutr. 1973, 30, 297.

8. Broad, T.; Nutritional Biochemistry, $2^{\text {nd }}$ ed., Academic Press: San Diego, 1999.

9. National Research Council; Recommended Dietary Allowances, $10^{\text {th }}$ ed., National Academic Press: Washington, 1989.

10. Bechgaard, H.; Jespersen, S.; J. Pharm. Sci. 1977, 66, 871; van der Berg, H.; Eur. J. Clin. Nutr. 1997, 51(suppl.1), S64; Nabokina, S. M.; Kashyap, M. L.; Said, H. M.; Am. J. Physiol. Cell Physiol. 2005, 289, C97.

11. Said, H. M.; Nabokina, S. M.; Balamurugan, K.; Mohammed, Z. M.; Urbina, C.; Kashyap, M. L.; Am. J. Physiol. Cell Physiol. 2007, 293, C1773.

12. Santos, R. D.; Arq. Bras. Cardiol. 2005, 85 (supl. V), 17.

13. Hegyi, J.; Schwartz, R. A.; Hegyi, V.; Int. J. Dermatol. 2004, 43, 1.

14. McCormick, D. B. Em Modern Nutrition in Health and Disease; Shils, M. E.; Young, V. R., eds.; Lea and Febiger: Philadelphia, 1988.
15. Darvay, A.; Basarab, T.; McGregor, J. M.; Russell-Jones, R.; Clin. Exp. Dermatol. 1999, 24, 167.

16. Murray, M. F.; Lancet Infect. Dis. 2003, 3, 644.

17. Nogueira, A.; Duarte, A. F.; Magina, F.; Azevedo, F.; Dermatol. Online J. 2009, 15, 8 .

18. Zhang, J. Z.; Henning, S. M.; Swenseid, M. E.; J. Nutr. 1993, 123, 1349.

19. Spronck, J. C.; Nickerson, J. L.; Kirkland, J. B.; Nutr. Cancer 2007, 57, 88.

20. Spronck, J. C.; Kirkland, J. B.; Mutat. Res. 2002, 508, 83; Kostecki, L. M.; Thomas, M.; Linford, G.; Lizotte, M.; Toxopeus, L.; Bartleman, A. P.; Kirkland, J. B.; Mutat. Res. 2007, 625, 50.

21. Xydakis, A. M.; Jones, P. H.; Curr. Atheroscler. Rep. 2003, 5, 403; Shek, A.; Ferrill, M. J.; Ann. Pharmacother. 2001, 35, 908.

22. Knip, M.; Douek, I. F.; Moore, W. P.; Gillmor H. A.; McLean, A. E.; Bingley, P. J.; Gale, E. A.; Diabetologia 2000, 43, 1337.

23. Hendler, S. S.; Rorvik, D. Em PDR for Nutritional Supplerments; Hendler, S. S.; Rorvik, D., eds.; Medical Economics/Thomson Healthcare: Nova Jersey, 2001.

24. Kaanders, J. H.; Pop, L. A.; Marres, H. A.; van der Maazen, R. W.; van der Kogel, W. A.; Radiother. Oncol. 1995, 37, 190.

25. Messamore, E.; Prostaglandins, Leukotrienes Essent. Fatty Acids 2003, $69,413$.

26. Oberwittler, H.; Baccara-Dinet, M.; Int. J. Clin. Pract. 2006, 60, 707.

27. Kirkland, J. B.; Nutr. Cancer 2003, 46, 110.

28. Nomura, K.; Shin, M.; Sano, K.; Umezawa, C.; Shimada, T.; Int. J. Vitam. Nutr. Res. 1983, 53, 36.

29. Friedrich, W.; Vitamins, Walter de Gruyter \& Co.: Berlin, 1988.

30. Sauberlich, H. E.; Dowdy, R. P., Skala, J. H.; Laboratory Tests for the Assessment of Nutritional Status, CRC Press: Florida, 1974.

31. Creeke, P. I.; Seal, A. J.; J. Chromatogr., B: Anal. Technol. Biomed. Life Sci. 2005, 817, 247; Okamoto, H.; Ishikawa, A.; Yoshitake, Y.; Kodama, N.; Nishimuta, M.; Fukuwatari, T.; Shibata, K.; Am. J. Clin. Nutr. 2003, 77, 406.

32. Shibata, K.; Matsuo, H.; J. Nutr. 1989, 119, 896.

33. Jacob, R. A.; Swendseid, M. E.; McKee, R. W.; Fu, C. S.; Clemens, R. A.; J. Nutr. 1989, 119, 591.

34. Slominska E. M.; Rutkowski, B.; Smolenski, J.; Mol. Cell Biochem. 2004, 267, 25.

35. Vivian V. M.; Chaloupka, M. M.; Reynolds, M. S.; J. Nutr. 1958, 66, 587.

36. Jacobson, E. L.; Jacobson, M. K.; Methods Enzymol. 1997, 280, 221.

37. Fu, C. S.; Swendseid, M. E.; Jacob, R. A.; Mckee, R. W.; J. Nutr. 1989, 119, 1949.

38. Jacobson, E. L.; Lange, R. A.; Jacobson, M. K.; J. Cell Physiol. 1979, 99, 417 . 
39. Coomes, M. W. Em Textbook of Biochemistry with Clinical Correlations; Devlin, T. M., ed.; John Wiley \& Sons: Massachusetts, 2006, cap. 19.

40. Patterson, J. I.; Brown, R. R.; Linkswiler, H.; Harper, A. E.; Am. J. Clin. Nutr. 1980, 33, 2157.

41. Shibata, K.; Adv. Exp. Med. Biol. 1999, 467, 711.

42. Rose, D. P.; Braidman, I. P.; Am. J. Clin. Nutr. 1971, 24, 673.

43. International Life Sciences Institute; Nutr. Rev. 1986, 44, 26.

44. Bender, D. A.; Br. J. Nutr. 1989, 61, 629.

45. Magni, G.; Amici, A.; Emanuelli, M.; Orsomando, G.; Raffaelli, N.; Ruggieri S.; Cell Mol. Life Sci. 2004, 61, 19.

46. Bender, D. A.; Olufunwa, R.; Br. J. Nutr. 1988, 59, 279.

47. Bernofsky, C.; Mol. Cell Biochem. 1980, 33, 135.

48. Nelson, D. L.; Cox, M. M.; Lehninger, Principles of Biochemistry, $4^{\text {th }}$ ed., W. H. Freeman and Company: New York, 2005.

49. Guse, A. H.; Curr. Mol. Med. 2002, 2, 273.

50. Kirkland, J. B.; Exp. Biol. Med. 2010, 235, 561.

51. Aarhus, R.; Dickey, D.; Graeff, R. M.; Gee, K. R.; Walseth, T. F.; lee, H. C.; J. Biol. Chem. 1996, 271, 8513.

52. Dammemann, W.; Guse, A. H.; J. Biol. Chem. 2005, 280, 21394.

53. Dammemann, W.; Zhang, B.; Nebel, M.; Cordiglieri, C.; Odoardi, F.; Kirchberger, T.; Kawakami, N.; Dowden, J.; Schmid, F.; Dornmair, K.; Hohenegger, M.; Flügel, A.; Guse, A. H.; Potter, B. V.; Proc. Natl. Acad. Sci. 2009, 106, 10678; Cordiglieri, C.; Odoardi, F.; Zhang, B.; Nebel, M.; Kawakami, N.; Klinkert, W. E.; Lodygin, D.; Lühder, F.; Breunig, E.; Schild, D.; Ulaganathan, V. K.; Dornmair, K.; Dammermann, W.; Potter, B. V.; Guse, A. H.; Flügel, A.; Brain 2010, 133, 1930; Guse, H.; Curr. Biol. 2009, 19, 521.

54. Kirkland, J. B.; J. Nutr. 2009, 139, 2397.

55. Satoh, M. S.; Poirier, G. G.; Lindahl, T.; J. Biol. Chem. 1993, 268, 5480.

56. Miwa, M.; Masutani, M.; Cancer Sci. 2007, 98, 1528.

56. Kirkland, J. B.; Curr. Pharm. Des. 2009, 15, 3.

57. Szabo, C.; Int. Care Med. 2003, 29, 863.

58. Virag, L.; Curr. Vasc. Pharmacol. 2005, 3, 209.

59. Denu, J. M.; Trends Biochem. Sci. 2005, 30, 479.

60. Yu, J.; Auwerx, J.; Ann. N. Y. Acad. Sci. 2009, 1173 (suppl. 1), 10.

61. Huang, J. Y.; Hirschey, M. D.; Shimazu, T.; Ho, L.; Verdin, E.; Biochim. Biophys. Acta 2010, 1804, 1645.

62. Yang, Y.; Cimen, H.; Han, M. J.; Shi, T.; Deng, J. H.; Koc, H.; Palacios, O. M.; Montier, L.; Bai, Y.; Tong, Q.; Koc, E. C.; J. Biol. Chem. 2010, $285,7417$.

63. Sauve, A. A.; Moir, R. D.; Schramm, V. L.; Willis, I. M.; Mol. Cell. 2005, 17, 595.

64. Bitterman, K. J.; Anderson, R. M.; Cohen, H. Y.; Latore-Esteves, M.; Sinclair, D. A.; J. Biol. Chem. 2002, 277, 45099.

65. Anderson, R. M.; Bitterman, K. J.; Wood, J. G.; Medvedik, O.; Sinclair, D. A.; Nature 2003, 423, 181.

66. Lombard, D. B.; Alt., F. W.; Cheng, H. L.; Bunkenborg, J.; Streeper, R. S.; Mostoslavsky, R.; Kim, J.; Yancopoulos, G.; Valenzuela, D.; Murphy, A.; Yang, Y.; Chen, Y.; Hirschey, M. D.; Bronson, R. T.; Haigis, M.; Guarente, L. P.; Farese, R. V. Jr.; Weissman, S.; Verdin, E.; Schwer, B.; Mol. Cell. Biol. 2007, 27, 8807.

67. Nakamura, Y.; Ogura, M.; Tanaka, D.; Inagaki, N.; Biochem. Biophys. Res. Commun. 2008, 366, 174.

68. Araki, T.; Sasaki, Y.; Milbrandt, J.; Science 2004, 305, 1010.

69. Mertz, W.; Nutr. Rev. 1975, 33, 129.

70. Niu. N.; Yu, Y. H.; Wang, Y.; Wang, L. J.; Li, Q.; Guo, L. M.; Mol. Biol. Rep. 2009, 36, 1275.

71. Agte, V. V.; Paknikar, K. M.; Chiplonkar, S. A.; Biometals 1997, 10, 271.

72. Altschul, R.; Hoffer, A.; Stephen, J. D.; Arch. Biochem. 1955, 54, 558.

73. Carlson, L. A.; J. Int. Med. 2005, 258, 94.

74. Canner, P. L.; Berge, K. G.; Wenger, N. K.; Stamler, J.; Friedman, L.; Prineas, R. J.; Friedewald, W.; J. Am. Coll. Cardiol. 1986, 8, 1245.
75. Berge, K. J.; Canner, P. L.; Eur. J. Clin. Pharmacol. 1991, 40 (suppl. 1), 49.

76. McKenney, J.; Arch. Intern. Med. 2004, 164, 697.

77. Rosenson, R. S.; Atherosclerosis 2003, 171, 87.

78. Santos, R. D.; Giannini, S. D.; Fonseca, F. A. H.; Arq. Bras. Cardiol. 2001, 77( supl. III), 1 .

79. Meyers, C. D.; Kamanna, V. S.; Kashyap, M. L.; Curr. Opin.Lipidol. 2004, 15, 659; Birjmohun, R. S.; Hutten, B. A.; Kastelein, J. J.; Stroes, E. S.; J. Am. Coll. Cardiol. 2005, 45, 185.

80. Gharbaoui, T.; Skinner, P. J.; Shin, Y. J.; Averbuj, C.; Jung, J. K.; Johnson, B. R.; Duong, T.; Decaire, M.; Uy, J.; Cherrier, M. C.; Webb, P. J.; Tamura, S. Y.; Zou, N.; Rodriguez, N.; Boatman, P. D.; Sage, C. R.; Lindstrom, A.; Xu, J.; Schrader, T. O.; Smith, B. M.; Chen, R., Richman, J. G.; Connolly, D. T.; Colletti, S. L.; Tata, J. R.; Semple, G.; Bioorg. Med. Chem. Lett. 2007, 17, 4914.

81. Carlson, L. A.; Oro, L.; Acta Med. Scand. 1962, 172, 641; Carlson, L. A.; Hanggren, A.; Life Sci. 1964, 3, 867; Butcher, R. W.; Baird, C. E.; Sutherland, E. W.; J. Biol. Chem. 1968, 243, 1705.

82. Aktories, K.; Jakobs, K. H.; Schultz, G.; FEBS Lett. 1980, 115, 11.5; Aktories, K.; Schultz, G.; Jakobs, K. H.; FEBS Lett. 1983, 156, 88.

83. Lorenzen, A.; Stannek, C.; Lang, H.; Andrianov, V.; Kalvinsh, I.; Schwabe, U.; Mol. Pharmacol. 2001, 59, 349; Lorenzen, A.; Stannek, C.; Burmeister, A.; Kalvinsh, I.; Schwabe, U.; Biochem. Pharmacol. 2002, 64, 645.

84. Wise, A.; Foord, S. M.; Fraser, N. J.; Barnes, A. A.; Elshourbagy, N.; Eilert, M.; Ignar, D. M.; Murdock, P. R.; Steplewski, K.; Green, A.; Brown, A. J.; Dowell, S. J.; Szekeres, P. G.; Hassall, D. G.; Marshall, F.H.; Wilson, S.; Pike, N.B.; J. Biol. Chem. 2003, 27, 9869.

85. Soga, T.; Kamohara, M.; Takasaki, J.; Matsumoto, S-I.; Saito, T.; Ohishi, T.; Hiyama, H.; Matsuo, A.; Matsushime, H.; Furuichi, K.; Biochem. Biophys. Res. Commun. 2003, 303, 364.

86. Pike, N.B.; Wise, A.; Curr. Opin. Investig. Drugs 2004, 5, 271.

87. Tunaru, S.; Kero, J.; Schaub, A.; Wufka, C.; Blaukat, A.; Pfeffer, K.; Offermanns, S.; Nature Med. 2003, 9, 352.

88. Tunaru, S.; Lattig, J.; Kero, J.; Krause, G.; Offermanns, S.; Mol. Pharmacol. 2005, 68, 1271.

89. Pike, N. B.; J. Clin. Invest. 2005, 115, 3400; Offermanns, S.; Trends Pharmacol. Sci. 2006, 27, 384.

90. Soudijn, W.; van Wijngaarden, I.; Ijzerman, A. P.; Med. Res. Rev. 2007, $27,417$.

91. Morton, R. E.; Greene, D. J.; Arterioscler. Thromb. Vasc. Biol. 1997, 17, 3041; Karpe, F.; Frayn, K. N.; Lancet 2004, 363, 1892.

92. Kobayashi, K.; Curr. Drug Targets 2005, 6, 525.

93. Westphal, S.; Borucki, K.; Taneva, E.; Makarova, R.; Luley, C.; Metabolism 2006, 55, 1283; Westphal, S.; Luley, C.; Atherosclerosis 2008, 198, 179 .

94. Digby, J. E.; McNeill, E.; Dyar, O. J.; Lam, V.; Greaves, D. R.; Choudhury, R. P.; Atherosclerosis 2010, 209, 89.

95. Kamanna, V. S.; Kashyap,M. L.; Am. J. Cardiol. 2008, 101, 20B.

96. Poynten, A. M.; Gan, S. K.; Kriketos, A. D.; O’Sullivan, A.; Kelly, J. J.; Ellis, B. A.; Chisholm, D. J.; Campbell, L. V.; Metabolism 2003, 52, 699.

97. Grundy, S. M.; Mok, H. Y. I.; Zech, L.; Berman, M.; J. Lipid Res. 1981, 22, 24.

98. Jin, F. Y.; Kamanna, V. S.; Kashyap, M. L.; Arterioscler. Thromb. Vasc. Biol. 1999, 19, 1051 .

99. Ganji, S. H.; Tavintharan, S.; Zhu, D.; Xing, Y.; Kamanna, V. S.; Kashyap, M. L.; J. Lipid Res. 2004, 45, 1835.

100. Kamanna V. S.; Ganji, S. H.; Kashyap, M. L.; Curr. Atheroscler. Rep. 2009, 11, 45.

101. Griffin, B. A.; Proc. Nutr. Soc. 1999, 58, 163; Koba, S.; Yokota, Y.; Hirano, T.; Ito, Y.; Ban, Y.; Tsunoda, F.; Sato, T.; Shoji, M.; Suzuki, H.; Geshi, E.; Kobayashi, Y.; Katagiri, T.; J. Atheroscler. Thromb. 2008, 15, 250. 
102. Blum, C. B.; Levy, R. I.; Eisenberg, S.; Hall, M.; Goebel, R. H.; Berman, M.; J. Clin. Invest. 1977, 60, 795; Shepherd, J.; Packard, C. J.; Patsch, J. R.; Gotto, M.; J. Clin. Invest. 1979, 63, 858.

103. Jin, F. Y.; Kamanna, V. S.; Kashyap, M. L.; Arterioscler. Thromb. Vasc. Biol. 1997, 7, 2020.

104. Andrikoula, M.; McDowell, I. F.; Diabetes Obes. Metab. 208, 10, 271; Schaefer, E. J.; Santos, R. D.; Asztalos, B. F.; Curr. Opin. Lipidol. 2010, $21,289$.

105. Martinez, L. O.; Jacquet, S.; Esteve, J. P.; Rolland, C.; Cabezon, E.; Nature 2003, 421, 75; Zhang, L. H.; Meyers, C. D.; Kamanna, V. S.; Kashyap, M. L.; Artrioscler. Thromb. Vasc. Biol. 2006, 26, E-53.

106. Wu, Z. H.; Zhao, S. P.; Pharmacology 2009, 84, 282.

107. Rubic, T.; Trottmann, M.; Lorenz, R. L.; Biochem. Pharmacol. 2004, 67, 411.

108. Majdalawieh, A.; Ro, H. S.; Nucl. Recept.Signal. 2010, 8, e004.

109. Skinner, P. J.; Cherrier, M. C.; Webb, P. J.; Sage, C. R.; Dang, H. T.; Pride, C. C.; Chen, R.; Tamura, S. Y.; Richman, J. G.; Connolly, D. T.; Semple, G.; Bioorg. Med. Chem. Lett. 2007, 17, 6619.

110. Gharbaoui, T.; Skinner, P. J.; Shin, Y. J.; Averbuj, C.; Jung, J. K.; Johnson, B. R.; Duong, T.; Decaire, M.; Uy, J.; Cherrier, M. C.; Webb, P. J.; Tamura, S. Y.; Zou, N.; Rodriguez, N.; Boatman, P. D.; Sage, C. R.; Lindstrom, A.; Xu, J.; Schrader, T. O.; Chen, R.; Richman, J. G.; Connolly, D. T.; Colletti, S. L.; Semple, G.; Smith, B. M.; Bioorg. Med. Chem. Lett. 2007, 17, 4914; Shen, H. C.; Expert Opin. Ther. Pat. 2009, 19, 1149; Shen, H. C.; Taggart, A. K.; Wilsie, L. C.; Waters, M. G.; Hammond, M. L.; Tata, J. R.; Colletti, S. L.; Bioorg. Med. Chem. Lett. 2008, 18, 4948.

111. Shen, H. C.; Szymonifka, M. J.; Kharbanda, D.; Deng, Q.; CarballoJane, E.; Wu, K. K.; Wu, T. J.; Cheng, K.; Ren, N.; Cai, T. Q.; Taggart, A. K.; Wang, J.; Tong, X.; Waters, M. G.; Hammond, M. L.; Tata, J. R.; Colletti, S. L.; Bioorg. Med. Chem. Lett. 2007, 17, 6723.

112. Mahboubi, K.; Witman-Jones, T.; Adamus, J. E.; Letsinger, J. T.; Whitehouse, D.; Moorman, A. R.; Sawicki, D.; Bergenhem, N.; Ross, S. A.; Biochem. Biophys. Res. Commun. 2006, 340, 482; Jung, J. K.; Johnson, B. R.; Duong, T.; Decaire, M.; Gharbaoui, T.; Boatman, P. D.; Sage, C. R.; Chen, R.; Richman, J. G.; Connolly, D. T.; Semple, G.; J. Med. Chem. 2007, 50, 1445.

113. Martres, P.; Curr. Top. Med. Chem. 2009, 9, 428.

114. Semple, G.; Skinner, P. J.; Cherrier, M. C.; Webb, P. J.; Sage, C. R.; Tamura, S. Y.; Chen, R.; Richman, J. G.; Connolly, D. T.; J. Med. Chem. 2006, 49, 1227.

115. Benyó, Z.; Gille, A.; Kero, J.; Csiky, M.; J. Clin. Invest. 2005, 192, 253; Maciejewski-Lenoir, D.; Richman, J. G.; Hakak, Y.; Gaidarov, I.; Behan, D. P.; Connolly, D. T.; J. Invest. Dermatol. 2006, 126, 2637.

116. Morrow, J. D.; Parsons, W. G.; Roberts L. J.; Prostaglandins 1989, 38 , 263; Morrow, J. D.; Awad, J. A.; Oates, J. A.; Roberts, L. J.; J. Invest. Dermatol. 1992, 98, 812.

117. Kamanna V. S.; Ganji, S. H.; Kashyap, M. L.; Int. J. Clin. Pract. 2009, 63, 1369; Cheng, K.; Wu, T. J.; Sturino, C.; Metters, K.; Gottesdiener, K.; Wright, S. D.; Wang, Z.; O'Neill, G.; Lai, E.; Waters, M. G.; Proc. Natl. Acad. Sci. 2006, 103, 6682.

118. Sood, A.; Arora, R.; J. Clin. Hypertension 2009, 11, 685.

119. Papaliodis, D.; Boucher, W.; Kempuraj, D.; Michaelian, M.; Wolfberg, A.; House, M.; Theoharides, T. C.; J. Pharmacol. Exp. Ther. 2008, 327, 665 .

120. Kalogeromitros, D.; Makris, M.; Chliva, C.; Aggelides, X.; Kempuraj, D.; Theoharides, T. C.; Int. J. Immunophatol. Pharmacol. 2008, 21, 509.

121. Vosper, H.; Br. J. Pharmacol. 2009, 158, 429; Tuohimaa, P.; Järvilehto, M.; Med. Hypotheses 2010, 75, 397.

122. Knowles, H. J.; Poele, R. H.; Workman, P.; Harris, A. L.; Biochem. Pharmacol. 2006, 71, 646.

123. Hoffer, L. J.; Isr. J. Psychiatry Relat. Sci. 2008, 45, 3.

124. Petrie, W. M.; Ban, T. A.; Drugs 1985, 30, 58.
125. Cho, K. H.; Kim, H. J.; Rodríguez-Iturbe, B.; Vaziri, N. D.; Am. J. Physiol. Renal Physiol. 2009, 297, F106; Cho, K. H.; Kim, H. J.; Kamanna, V. S.; Vaziri, N. D.; Biochim. Biophys. Acta 2010, 1800, 6.

126. Liu, H. K.; Green, B. D.; Flatt, P. R.; McClenaghan, N. H.; McCluskey, J. T.; Endocr. Res. 2004, 30, 61; Yoshinari, O.; Igarashi, K.; Curr. Med. Chem. 2010, 17, 2196; Athyros, V. G.; Tziomalos, K.; Karagiannis, A.; Mikhailidis, D. P.; Expert Opin. Pharmacother. 2010, 11, 1965.

127. Talpur, N.; Echard, B. W.; Yasmin, T.; Bagchi, D.; Preuss, H. G.; Mol. Cell Biochem. 2003, 252, 369.

128. Greenbaum, C. J.; Kahn, S. E.; Palmer, J. P.; Diabetes 1996, 45, 1631.

129. Ahmed, M. H.; J. Cardiovasc. Med. 2010, 11, 858.

130. Stanulovic, M.; Chaykin, S.; Arch. Biochem. Biophys. 1971, 145, 35; Stanulovic, M.; Chaykin, S.; Arch. Biochem. Biophys. 1971, 145, 27.

131. Bertolami, M. C.; Arq. Bras. Cardiol. 2005, 85(supl. 5), 25.

132. Lee, W. M.; New Engl. J. Med. 2003, 349, 474; Jaeschke, H.; Gores, G. J.; Toxicol. Sci. 2002, 65, 166.

133. Rodwell, V. W.; Harper's Illustrated Biochemistry, $27^{\text {th }}$ ed., McGrawHill: New York, 2006, cap. 27.

134. Botham, K. M.; Mayes, P. A. em ref. 134, cap. 25.

135. Karas, R. H.; Kashyap, M. L.; Knopp, R. H.; Keller, L. H.; Bajorunas, D. R.; Davidson, M. H.; Am. J. Cardiovasc. Drugs 2008, 8, 69.

136. Fazio, S.; Guyton, J. R.; Polis, A. B.; Adewale, A. J.; Tomassini, J. E.; Ryan, N. W.; Tershakovec, A. M.; Am. J. Cardiol. 2010, 105, 487.

137. McCormack, P. L.; Keating, G. M.; Drugs 2005, 65, 2719.

138. Vogt, A.; Kassner, U.; Hostalek, U.; Steinhagen-Thiessen, E.; Curr. Med. Res. Opin. 2006, 22, 417.

139. Birjmohum, R. S.; Kastelein, J. J.; Poldermans, D.; Stroes, E. S.; Hostalek, U.; Assmann, G.; Curr. Med. Res. Opin. 2007, 23, 1707.

140. Knopp, R. H.; Am. J. Cardiol. 2000, 86, 51L.

141. Parhofer, K. G.; Vasc. Health Risk Manag. 2009, 5, 901; Paolini, J. F.; Bays, H. E.; Ballantyne, C. M.; Davidson, M.; Pasternak, R.; Maccubbin, D.; Norquist, J. M.; Lai, E.; Waters, M. G.; Kuznetsova, O.; Sisk, C. M.; Mitchel, Y. B.; Cardiol. Clin. 2008, 26, 547; Paolini, J. F.; Mitchel, Y. B.; Reyes, R.; Thompson-Bell, S.; Yu, Q.; Watson, D. J.; Norquist, J. M.; Sisk, C. M.; Bays, H. E.; Int. J. Clin. Pract. 2008, 62, 896; Perry, C. M.; Drugs 2009, 69, 1665; Olsson, A. G.; Expert Opin. Pharmacother. 2010, 11, 1715.

142. Davidson, M. H.; Curr. Atheroscler. Rep. 2003, 5, 418.

143. Blankenhorn, D. H.; Johnson, R. L.; Nessim, S. A.; Azen, S. P.; Sanmarco, M. E.; Selzer, R. H.; Control Clin. Trials 1987, 8, 356; Blankenhorn, D. H.; Nessim, S. A.; Johnson, R. L.; Sanmarco, M. E.; Azen, S. P.; Cashin-Hemphill; JAMA 1987, 257, 3233.

144. Cashin-Hemphill, L.; Mack, W. J.; Pogoda, J. M.; Sanmarco, M. E.; Azen, S. P.; Blankenhorn, D. H.; JAMA 1990, 264, 3013.

145. Moon, Y. S.; Kashyap, M. L.; Expert Opin. Pharmacother. 2002, 3, 1763.

146. Gupta, E. K.; Ito, M. K.; Heart Dis. 2002, 4, 124; Yim, B. T.; Chong, P. H.; Ann. Pharmacother. 2003, 37, 106; Zhao, X. Q.; Morse, J. S.; Dowdy, A. A.; Heise, N.; DeAngelis, D.; Frohlich, J.; Chait, A.; Albers, J. J.; Brown, B. G.; Am. J. Cardiol. 2004, 93, 307; Ballantyne, C. M.; Davidson, M. H.; McKenney, J.; Keller, L. H.; Bajorunas, D. R.; Karas, R. H.; Am. J. Cardiol. 2008, 101, 1428; Sanford, M.; Curran, M. P.; Drugs 2008, 68, 2373; Zhao, X. Q.; Krasuski, R. A.; Baer, J.; Whitney, E. J.; Neradilek, B.; Chait, A.; Marcovina, S.; Albers, J. J.; Brown, B. G.; Am. J. Cardiol. 2009, 104, 1457; Airan-Javia, S. L.; Wolf, R. L.; Wolfe, M. L.; Tadesse, M.; Mohler, E.; Reilly, M. P.; Am. Heart J. 2009, 157, 687 .

147. Taylor, A. L.; Sullenberger, L. E.; Hyun, J.; Lee, H. J.; Lee, J. K.; Grace, K. A.; Circulation 2004, 7, 3512.

148. Bays, H. E.; Dujovne, C. A.; McGovern, M. E.; White, T. E.; Kashyap, M. L.; Hutcheson, A. G.; Crouse, J. R.; Am. J. Cardiol. 2003, 91, 667; Bays, H. E.; Expert Rev. Cardiovasc. Ther. 2004, 2, 485.

149. Bays, H. E.; McGovern, M. E.; Prev. Cardiol. 2003, 6, 179. 
150. Sharma, M.; Sharma, D. R.; Singh, V.; Panwar, R. B.; Hira, H. S.; Mohan, B.; Kumar, N.; Sharma, S. K.; Gupta, R.; Vasc. Health Risk Manag. 2006, 2, 87.

151. Vittone, F.; Chait, A.; Morse, J. S.; Fish, B.; Brown, B. G.; Zhao, X. Q.; J. Clin. Lipidol. 2007, 1, 203.

152. Bays, H. E.; McGovern, M. E.; Prev. Cardiol. 2005, 8, 226.

153. Taylor, A. J.; Lee, H. J.; Sullenberger, L. E.; Curr. Med. Res. Opin. 2006, $22,2243$.

154. Taylor, A. J.; Zhu, D.; Sullenberger, L. E.; Lee, H. J.; Lee, J. K.; Grace, K. A.; Vasc. Health Risk Manag. 2007, 3, 159.

155. Taylor, A. J.; Villines, T. C.; Stanek, E. J.; Devine, P. J.; Griffen, L.; Miller, M.; Weissman, N. J.; Turco, M.; New Engl. J. Med. 2009, 361, 2113.
156. Villines, T. C.; Stanek, E. J.; Devine, P. J.; Turco, M.; Miller, M.; Weissman, N. J.; Griffen, L.; Taylor, A. J.; J. Am. Coll. Cardiol. 2010, 55, 2721.

157. Araújo, R. G.; Filho, A. C.; Chagas, A. C. P.; Arq. Bras. Cardiol. 2005, 85(supl. 5), 20.

158. Guyton, J. R.; Brown, B. G.; Fazio, S.; Polis, A.; Tomassini, J. E.; Tershakovec, A. M.; J. Am. Coll. Cardiol. 2008, 51, 1564.

159. Cheung, M. C.; Zhao, X. Q.; Chait, A.; Albers, J. J.; Brown, B. G.; Arterioscler. Thromb. Vasc. Biol. 2001, 21, 1320.

160. Brown, B. G.; Zhao, X. Q.; Chait, A.; Fisher, L. D.; Cheung, M. C.; Morse, J. S.; Dowdy, A. A.; Marino, E. K.; Bolson, E. L.; Alaupovic, P.; Frohlich, J.; Albers, J. J.; New Engl. J. Med. 2001, 345, 1583. 